Universidade de Brasília

IP - Instituto de Psicologia

Departamento de Processos Psicológicos Básicos (PPB)

Programa de Pós-Graduação em Ciências do Comportamento

Controle discriminativo em metacontingência

Rafaela Meireles Fontes Azevedo

Brasília, Janeiro de 2015. 


\title{
Controle discriminativo em metacontingência
}

\author{
Rafaela Meireles Fontes Azevedo
}

Dissertação apresentada ao programa de Pós-Graduação em Ciências do Comportamento do departamento de Processos Psicológicos Básicos, Instituto de Psicologia da Universidade de Brasília, como requisito parcial à obtenção do grau de Mestre em Ciências do Comportamento.

Orientador: Dr. João Claudio Todorov

Brasília, Janeiro de 2015. 
Este trabalho foi desenvolvido no Instituto de Psicologia da Universidade de Brasília com apoio da CAPES.

\section{Comissão Examinadora}

Prof. Dr. João Claudio Todorov (Presidente)

Universidade de Brasília

Prof $^{a}$. Dr ${ }^{\mathrm{a}}$. Raquel Aló (Membro Efetivo)

Universidade de Brasília

Prof. Dr. Márcio Moreira Borges (Membro Efetivo)

Centro Universitário de Brasília

Prof $^{\mathrm{a}}$. Dra ${ }^{\mathrm{a}}$. Raquel Maria de Melo (Membro Suplente)

Universidade de Brasília 


\section{Índice}

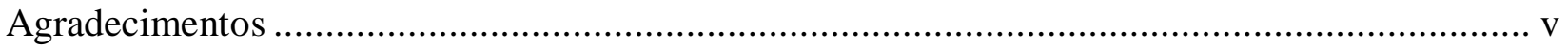

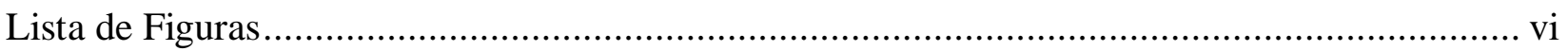

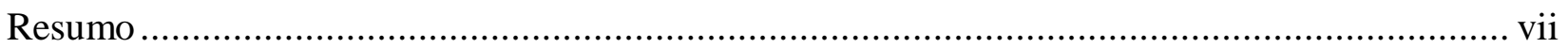

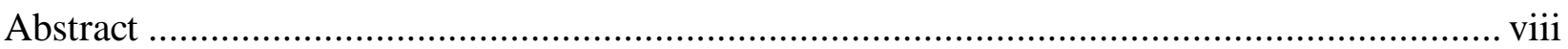

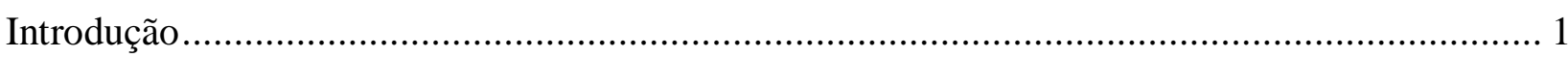

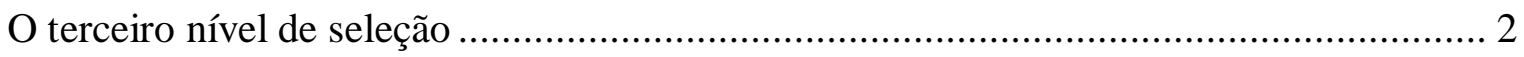

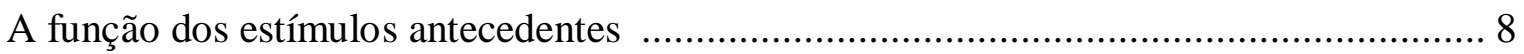

Controle de estímulos em contextos sociais....................................................... 15

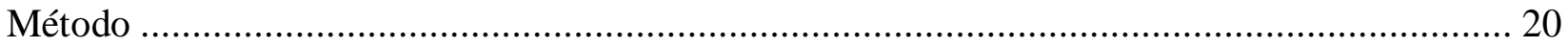

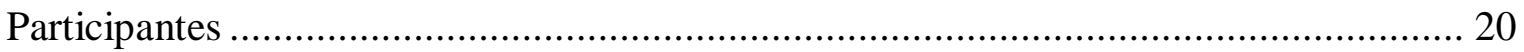

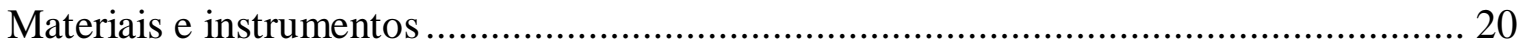

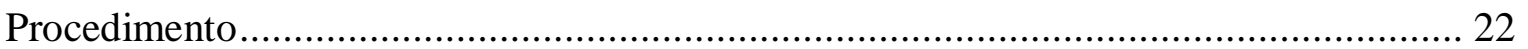

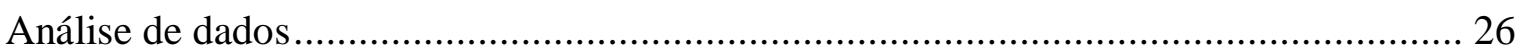

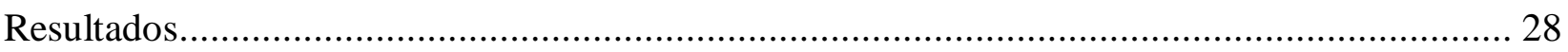

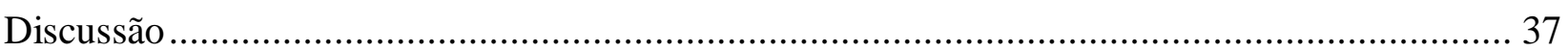

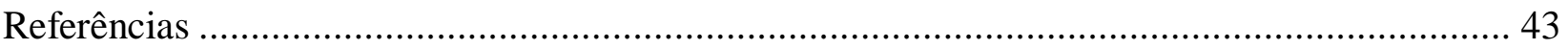

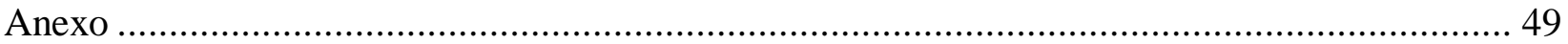




\section{Agradecimentos}

De nada adianta chegar ao fim de uma etapa se não tivermos um coração grato a todos aqueles que tornaram essa realização possível. A jornada de um mestrado, embora curta, pode ser bastante árdua. Ao chegar ao final, maior do que o alívio de enfim ter terminado, é a alegria de poder dizer muito obrigada a todos aqueles quem estiveram presentes e contribuíram de algum forma para tornar tudo isso possível.

Tenho um coração grato a Deus, que durante esses dois anos longe de casa e da minha família, não me desamparou em nenhum momento.

Agradeço à minha família, e especialmente aos meus pais (Rosa, Márcio e Yano) e ao meu irmão Luan, que sempre me apoiaram e conseguiram se fazer presente durante todo esse tempo, independente dos quilômetros que nos separavam.

Agradeço ao professor Todorov que tão pacientemente me conduziu e me agraciou com a sua sabedoria ao longo desses anos e com quem tem sido um enorme prazer trabalhar.

Sou muito grata à Diogo Seco, quem me iniciou na Análise do Comportamento e foi o maior incentivador para que eu investisse na carreira acadêmica.

Aos demais professores do departamento e, especialmente, à Eileen Flores que foi minha supervisora durante o estágio em docência e me ensinou como tentar ser cada vez melhor para os meus alunos, ao Carlos Cançado e à Raquel Aló que mudaram completamente a minha relação com a Análise do Comportamento, fazendo eu me apaixonar cada vez mais pela área e reconhecer o tamanho da minha ignorância frente ao universo que é o campo da experimentação, e à Josele Abreu pela oportunidade de participar do seu grupo de pesquisa, cujas discussões aguçaram meu senso crítico em relação a minha área de estudo.

Ao João Vianney, que tornou esse trabalho possível e que foi tão paciente e solícito ao longo de todo o processo, desenvolvendo inúmeras versões do software para adequá-lo às necessidades do experimento.

Agradeço a banca pelo aceite do meu convite e, principalmente, pelas contribuições que certamente serão muito importantes para que eu possa aprimorar o meu trabalho.

Sou grata aos funcionários do PPB (Joyce, Daniel e Rodolfo), sempre solícitos, simpáticos e pacientes em ajudar de todas as maneiras possíveis. E à CAPES pelo auxílio financeiro.

Sou absolutamente grata a todos aqueles que tornaram a minha vida em Brasília mais agradável. Aos colegas da pós (Fabi, Robs, Marcelo, Rodrigão, Paulo e Fabio), de quem enchi tanto o saco com dúvidas e pedidos de ajuda, e com quem também compartilhei tantos momentos de alegria e diversão. Ao João, ao Pretto e ao Balduco, que me abrigaram e foram mais do que uma família pra mim. À Gaga, que há tantos anos está na minha vida provando que para as verdadeiras amizades não existe distância e que, durante esses dois anos, compartilhou comigo todas as alegrias e tristezas.

E agradeço, especialmente, a Tiago pelos seus ouvidos sempre pacientes com todas as minhas reclamações e desabafos e pelo ombro sempre disponível pra acalmar todo meu desespero.

A todos esses, e a todos aqueles que mesmo não tendo sido diretamente citados eu carrego sempre no coração, fica aqui o meu MUITO OBRIGADA! Nada disso seria possível sem vocês! 


\section{Lista de Figuras}

Figura 1. Tabuleiro na condição $S^{\mathrm{D}}$

Figura 2. Tabuleiro na condição $S^{\Delta}$

Figura 3. Gráficos de taxa de produto agregado por minuto, em cada tentativa ao longo das fases: Linha de Base, Treino de Discriminação e Teste de Discriminação. Cada gráfico se refere a uma dupla. Note que os valores do eixo y variam para cada dupla. .29

Figura 4. Taxa de produto agregado por minuto ao longo da fase de Teste de Generalização. Note que o eixo y varia para cada dupla.

Figura 5. Gráficos de número de movimentos, em cada tentativa, ao longo das condições experimentais (exceto Teste de Generalização). Cada gráfico se refere a uma dupla. Note que os valores do eixo y variam para cada dupla. .33

Figura 6. Na coluna da esquerda, gráficos indicando a dispersão no uso das células ao longo das condições para cada dupla. Na coluna da direita, gráficos indicando a dispersão da localização do Produto Agregado ao longo das condições para cada dupla. .35 


\section{Resumo}

Metacontingência, definida como um conjunto de contingências comportamentais entrelaçadas que produzem um produto agregado mantido por uma consequência, é uma unidade de análise no nível cultural, análoga à tríplice contingência. Estudos realizados na área têm tratado a metacontingência como uma contingência de dois termos, desconsiderando a função dos estímulos antecedentes. Em função da importância dos estímulos discriminativos sobre a emissão do comportamento, e na tentativa de estudar os processos básicos envolvidos no terceiro nível de seleção, o presente estudo teve como objetivo investigar os efeitos do processo de discriminação neste nível. O procedimento, que foi realizado a partir de um jogo colaborativo em um tabuleiro virtual e teve como produto agregado o encontro das peças, contou com quatro fases: Linha de Base, Treino de Discriminação, Teste de Discriminação e Teste de Generalização. Participaram do experimento 22 estudantes universitários, distribuídos em 11 duplas. Cada dupla passou pelas quatro fases e participou da atividade apenas uma vez. As medidas observadas foram: taxa de produto agregado ao longo das quatro fases, número de movimentos realizados e índice de dispersão. Os resultados indicam que houve um responder diferencial entre os estímulos que sinalizavam as diferentes contingências em vigor, embora os dados no Teste de Generalização não tenham sido sistemáticos. Outro efeito observado foi o de contraste comportamental quando houve a introdução da condição de extinção na fase de Treino. Os dados relacionados ao número de movimentos e índice de dispersão demonstraram a estereotipia gerada pelo reforçamento e variabilidade induzida pela extinção, ambos efeitos observados no comportamento operante. $\mathrm{O}$ experimento mostrou ser possível o estabelecimento da ocorrência do produto agregado manipulando-se apenas as consequências culturais e o estabelecimento de controle discriminativo contingente ao comportamento de mais de um indivíduo simultaneamente.

Palavras-chave: metacontingência; controle de estímulos; discriminação operante; estímulo discriminativo; contraste comportamental. 


\begin{abstract}
Metacontingency, defined as a set of interlocking behavioral contingencies that produce an aggregate product maintained by a consequence, is a unit of analysis in the cultural level, similar to the triple contingency. Studies in this area have treated the metacontingency as a contingency of two terms, disregarding the role of antecedent stimuli. Because of the importance of discriminative stimuli on the emission of behavior, and in an attempt to study the basic processes involved in the third level of selection, this study aimed to investigate the effects of the discrimination process in this level. The procedure, which was performed from a collaborative game on a virtual board and defined the aggregated product as the meeting of the pieces, consisted of four phases: Baseline, Discrimination Training, Discrimination Test and Generalization Test. Twenty two university students, distributed in 11 pairs, participated in the experiment. Each pair was exposed to the four phases and participated in the activity only once. The measures observed were: aggregate product rate over the four phases, the number of movements and dispersion index. The results indicate that there was a differential respond between the stimuli, although the generalization test data was not systematic. Another effect observed was the behavioral contrast when there was the introduction of an extinction condition in the training phase. The data relating to the number of movements and dispersion index showed the stereotype pattern generated by the reinforcement and variability induced by extinction, both effects observed in operant behavior. The experiment showed to be possible to establish the occurrence of aggregate product from manipulating only the cultural consequences and to establish the stimulus control over the behavior of more than one individual simultaneously.
\end{abstract}

Keywords: metacontingency; stimulus control; operant discrimination; discriminative stimulus; behavioral contrast. 
Skinner (1981) compreende o comportamento operante como sendo sensível às suas consequências, por isso selecionado por elas. O autor descreve o processo pelo qual o comportamento é determinado a partir de três níveis de seleção: 1) filogenético (onde características específicas da espécie e relacionadas à sobrevivência serão selecionadas); 2) ontogenético (relacionado à história individual de cada organismo - seleção do comportamento pelas suas consequências) e; 3) cultural (relacionado à transmissão de práticas culturais de geração a geração).

Apesar de afirmar que o comportamento é determinado por estes três níveis (filogenético, ontogenético e cultural), Skinner (1953/2003) deixa claro que o seu interesse se encontra no nível ontogenético e que a sua ciência se propõe a explicar o comportamento no nível individual - como as contingências atuam sobre o comportamento e a maneira como as consequências selecionam as classes de resposta. Sua teoria se baseia no estudo do comportamento operante - comportamento que opera no ambiente - e a unidade de análise para este nível de seleção são as contingências de reforçamento, que descrevem as relações funcionais entre o comportamento e o ambiente no qual ele atua.

A tríplice contingência (antecedente-resposta-consequência), proposta por Skinner, tem sido a ferramenta utilizada para o estudo e compreensão do comportamento operante, por permitir a análise funcional de uma relação entre comportamento e ambiente. Apesar do seu enorme uso e da sua utilidade já demonstrada para o estudo do comportamento, a tríplice contingência é uma unidade de análise a nível individual, nem sempre possibilitando a explicação de fenômenos a nível cultural, que extrapolam as contingências individuais por envolverem o comportamento de grupos de indivíduos - os chamados comportamentos sociais (Glenn, 1986). 


\section{O terceiro nível de seleção}

Embora a proposta de uma ciência do comportamento se centre em explicar o nível ontogenético de seleção e como o comportamento do indivíduo se estabelece ao longo da sua história de vida, Skinner (1953/2003) demonstra também interesse em fenômenos que envolvem mais de um indivíduo atuando no que ele chamou de comportamento social, “definido como o comportamento de duas ou mais pessoas em relação uma a outra ou em conjunto em relação ao ambiente comum” (p. 325). Sampaio e Andery (2010) afirmam que “o interesse especial da Análise do Comportamento pelo comportamento humano a obriga a tratar de fenômenos sociais" (p.183), compreendendo fenômenos sociais como eventos que envolvem o comportamento de mais de uma pessoa.

Um dos indicativos do interesse da Análise do Comportamento em dar conta também desses fenômenos que envolvem a ação conjunta de mais de um indivíduo são os estudos sobre cooperação realizados, principalmente, entre as décadas de 50 e 70. Alguns dos estudos seminais sobre cooperação são os de Azrin \& Lindsley (1954), Hake, Olvera \& Bell (1975), Schimitt (1976) e Schimitt \& Marwell, (1968, 1971a e 1971b). Esses estudos iniciais, entretanto, ainda fazem uso da tríplice contingência enquanto unidade de análise e explicam o comportamento a partir de contingências individuais que atuam simultaneamente sobre mais de um indivíduo, ou compreendem o comportamento de um estabelecendo as contingências para o comportamento do outro (atuando como estímulo discriminativo e reforço). A unidade básica nesses estudos é o episódio de cooperação e a sua ocorrência pode requerer respostas de ambos ou apenas um indivíduo, incluir reforços para ambos ou apenas um indivíduo, e ter a distribuição de tarefas e reforços igual ou desigual entre eles (Hake \& Vukelich, 1972).

Esses estudos sobre cooperação, entretanto, não abrangeram fenômenos sociais mais amplos, justamente por ainda trabalharem com as contingências que atuam no nível individual (exceto o primeiro, que já trabalha com a formação do produto agregado, embora 
ainda não utilize o termo). Para dar conta dos fenômenos que extrapolam as contingências individuais e que não são abarcados pela tríplice contingência enquanto unidade de análise, Glenn (1986) cunhou o termo metacontingência, definindo-o como a unidade de análise que descreve relações funcionais entre classes de operantes, cada uma tendo suas próprias consequências imediatas e também consequências a longo prazo comuns a todos os operantes envolvidos. A autora afirma ainda que as metacontingências devem ser mediadas por contingências de reforçamento socialmente arranjadas.

Independente da unidade de análise utilizada, seja ela a tríplice contingência ou a metacontingência, não se altera o entendimento de que "é sempre o indivíduo que se comporta, e que se comporta com o mesmo corpo e de acordo com os mesmos processos usados em uma situação não-social” (Skinner, 1953/2003, p. 326). Falar em metacontingência, então, não implica falar em comportamento de grupo, no sentindo de que grupos não se comportam, mas sim indivíduos.

Desde a criação do conceito muitos trabalhos analíticos a respeito de processos culturais históricos têm sido realizados, utilizando a metacontingência como ferramenta de análise (Lamal, 1991; Lamal \& Greenspoon, 1992; Rakos, 1991; Sénéchal-Machado \& Todorov, 2008; Todorov, 1987).

Além de funcionar como um outro nível de análise para os fenômenos sociais e históricos, "o desenvolvimento do conceito de metacontingência representa tentativa de formular uma estrutura conceitual unificada para a análise do comportamento social, propiciando também possibilidades para o planejamento de práticas culturais e, por conseguinte, de mudança social” (Martone e Todorov, 2007.p. 182).

Uma revisão sobre o desenvolvimento do conceito de metacontingência foi feita por Martone e Todorov (2007). No momento da criação do termo metacontingência (Glenn, 1986) é enfatizado o entrelaçamento das contingências que leva a uma consequência cultural 
comum. Aqui ainda não há referência sobre a recorrência dos entrelaçamentos. Os autores destacam ainda três contribuições importantes para o conceito: 1) a compreensão de que as contingências entrelaçadas geram um efeito agregado que atua como selecionador dos entrelaçamentos e, assim, permite a sua recorrência (Glenn, 1988); 2) adição do sistema receptor que fornece consequências que podem selecionar ou não o entrelaçamento das contingências (Glenn \& Malott, 2004); e 3) diferenciação entre relações de macrocontingência - processos de variação e seleção que ocorrem em nível individual e que tem como produto o efeito cumulativo de comportamentos que ocorrem de maneira independente (por exemplo, muitas pessoas andando de carro contribui para a poluição do ar, embora os comportamentos ocorram de maneira independente, levam ao um efeito cumulativo comum); e relações de metacontingência - processos de variação e seleção que ocorrem em nível cultural, resultando num produto agregado fruto de comportamentos entrelaçados (por exemplo, a montagem de um carro em uma fábrica, onde o comportamento de um depende do comportamento do outro para que se tenha o carro pronto como um produto agregado) (Malott \& Glenn, 2006).

Dentre uma das redefinições do conceito, a que tem sido mais utilizada nos trabalho da área atualmente é a de Glenn (2004) na qual a metacontingência é descrita como sendo contingências de seleção cultural envolvendo contingências comportamentais entrelaçadas (CCEs) que geram um produto agregado (PA), que é mais do que o acúmulo dos efeitos dos comportamentos individuais dos participantes. O produto gerado por essas contingências entrelaçadas afeta, então, a probabilidade de recorrência do entrelaçamento. O entrelaçamento pode ser selecionado tanto pelo produto agregado gerado por ele, quanto por uma consequência mediada socialmente que retroage sobre ambos (entrelaçamento e produto agregado). A recorrência das CCEs, entretanto, não exige, necessariamente, que participem 
sempre os mesmos indivíduos. Os membros que compõe as CCEs podem ser substituídos sem que a linhagem cultural seja perdida.

Enquanto para Glenn (2004) o produto agregado gerado na metacontingência retroage sobre as CCEs, selecionando-as, Todorov (2012a, 2012b) afirma que na metacontingência o que é selecionado não são as contingências entrelaçadas, mas o produto agregado. "Podemos dizer que a consequência seleciona um produto agregado, independentemente de variações nas CCEs. O importante são as características do PA. Potencialmente $\underline{\mathbf{n}}$ diferentes CCEs podem produzir o PA requerido pela metacontingência" (Todorov, 2012a, p. 39).

O autor também mostra que ainda há muita controvérsia no campo, e que o termo tem sido empregado a fim de descrever diferentes processos e procedimentos (Todorov, 2012b, 2013). Além da dificuldade em se definir o uso preciso do conceito, existem também dificuldades em estudá-lo empiricamente. Vasconcelos (2014) aponta três desafios no estudo experimental que faz uso da metacontingência enquanto unidade de análise: a falta de um procedimento bem estabelecido, a dificuldade em identificar as características definidoras do conceito, e a dificuldade no estabelecimento das variáveis dependentes e independentes para estudo do fenômeno.

Uma das principais questões metodológicas impostas a esse campo de pesquisa, pelos autores que tem trabalhado com este conceito atualmente, diz respeito à variável crítica a ser manipulada no sentido de produzir, em condições controladas de laboratório, a seleção de um entrelaçamento específico de muitos comportamentos ao longo do tempo, desencadeando a transmissão do que Glenn \& Malott (2004) denominam de 'linhagem cultural' (Martone \& Todorov, 2007, p. 182).

Algumas tentativas de se estudar o conceito experimentalmente têm sido realizadas e dois tipos de procedimentos principais têm sido empregados nesses estudos. O primeiro deles é o procedimento da matriz, utilizado por Vichi (2004) no primeiro estudo experimental que 
utiliza metacontingência, onde os participantes, que eram divididos em dois grupos, recebiam uma certa quantidade de fichas que deveriam ser distribuídas entre eles e, então, eram solicitados a fazerem apostas escolhendo uma linha numa matriz 8x8. O experimentador, então, escolhia uma coluna e caso a célula de interseção indicasse o símbolo "+” o grupo ganhava o dobro do apostado, caso o símbolo fosse “_“, ganhavam metade do valor apostado. O critério para a escolha da coluna era a forma de distribuição dos ganhos entre os grupos (divisão igual ou desigual dos valores) e o critério se invertia ao longo das condições. Foi observada que a forma de distribuição dos ganhos foi selecionada. Martone (2008) replicou o estudo de Vichi (2004) buscando investigar também aspectos específicos do entrelaçamento.

Pereira (2008) realizou uma série de experimentos utilizando um novo procedimento, a fim de estabelecer consequências individuais e culturais diferenciadas. Os experimentos foram realizados em um jogo de computador onde eram mostradas quatro janelas com números de 0 a 9 em uma linha e em uma segunda linha as células deveriam ser completadas pelos participantes com números também de 0 a 9. Caso a soma de cada uma das colunas fosse ímpar havia o ganho de pontos, caso uma das colunas desse uma soma par havia perda de pontos (consequências individuais). Já as consequências culturais (bônus) eram contingentes à relação entre a soma de todos os números inseridos por cada participante (a soma dos números do P1 deveria ser menor ou maior do que a soma do P2, por exemplo). Trabalhou-se também com a troca de gerações entre participantes.

Caldas (2009), utilizando o procedimento de Pereira (2008) investigou o efeito da suspensão da consequência cultural sobre produto agregado e observou efeitos de extinção, assim como no operante. Bullerjahnn (2009) replicou o mesmo procedimento aumentando o número de sujeitos que participavam das contingências comportamentais entrelaçadas (enquanto os estudos anteriores trabalharam com duplas, nesse trabalharam grupos de 4 pessoas). 
Os dados dos estudos citados não são sistemáticos. O que se observa é que frequentemente têm-se manipulado como variável independente as consequências (individuais ou culturais) a fim de verificar o efeito das contingências de reforçamento nas CCEs e em seus respectivos PAs. Vieira (2010) afirma:

até o momento, o que tem sido investigado experimentalmente em relação a metacontingências refere-se à contingência entre os entrelaçamentos e seus produtos agregados (CCEs $\rightarrow$ PA) e as consequências culturais. Tal relação é análoga à relação resposta-reforçador na contingência operante, ou a uma contingência básica de dois termos (p. 22, 23).

Outra característica desses experimentos iniciais que fazem uso da metacontingência é o seu nível de complexidade: procedimentos rebuscados, que envolvem manipulação de consequências a nível individual e cultural, troca de gerações de participantes, etc. É necessário, como primeiros passos, se buscar a unidade básica envolvida na metacontingência a fim de que seja possível estudar os princípios básicos envolvidos nos processos descritos que atuam no terceiro nível de seleção, assim como foi feito com o operante no laboratório (Todorov, 2012b). O exemplo mais simples a ser descrito por uma metacontingência seria aquele no qual participam apenas duas pessoas, onde os comportamentos de cada indivíduo funcionam como estímulo discriminativo e reforço para o comportamento do outro, havendo um produto agregado resultante desse entrelaçamento.

Além disso, observa-se também que os estudos têm tratado a metacontingência de maneira análoga a uma contingência de dois termos. Porém, no estudo do operante Skinner (1953/2003) afirma que os estímulos antecedentes à emissão do comportamento exercem 
uma função bastante relevante por sinalizarem a presença ou ausência de reforço. Todorov (2012b) afirma que

no ambiente natural raramente a contingência operante de dois termos (resposta e consequência) é válida para qualquer situação. É mais comum a observação de relações descritas pela contingência de três termos, ou tríplice: "se na situação S2 o comportamento R1 ocorrer, então a consequência S1 será apresentada (p. 51).

A função dos estímulos discriminativos que fazem parte da metacontingência, porém, tem sido negligenciada. Houmanfar e Rodrigues (2006) mencionam as condições antecedentes na metacontingência se referindo ao meio cultural no qual o grupo está inserido (entendendo o meio cultural como sendo composto por crenças, recursos materiais, regras, costumes e instituições constituídos e mantidos por um dado grupo social). Porém, os estímulos discriminativos, enquanto estímulos que estabelecem a ocasião em que as respostas terão consequência (Catania, 1999) não têm sido considerados nos estudos que se referem à metacontingências.

\section{A função dos estímulos antecedentes}

Um princípio geral que norteia a Análise do Comportamento é a compreensão de que o comportamento é controlado pelas suas consequências. Um segundo princípio geral é que o ambiente passa a controlar o comportamento a partir da relação que estabelece com as consequências reforçadoras (Sidman, 2008). Assim, o comportamento operante deve ser descrito em termos, tanto da sua relação com a consequência que o seleciona, quanto da sua relação com os estímulos antecedentes que estavam presentes na ocasião em que houve apresentação do reforço (Sério, Andery, Gioia \& Micheletto, 2002). 
Enquanto a sensibilidade aos estímulos antecedentes pode ser compreendida como um produto evolucionário, "o estabelecimento do controle de estímulos sobre a emissão da resposta é, por sua vez, produto de uma história específica de reforçamento" (Sério et al., 2002, p. 12). Terrace (1966a) define o controle de estímulos como sendo a extensão na qual um estímulo antecedente altera a probabilidade de emissão de uma resposta condicionada, sendo medido através da mudança gerada na probabilidade da resposta em função de mudanças no valor do estímulo antecedente.

Sendo o controle de estímulos fruto de uma história de reforçamento, entende-se, então, que essa história de reforçamento resulta na alteração da probabilidade de emissão da resposta: aumento da probabilidade na presença de determinados estímulos $\left(S^{\mathrm{D}}\right)$ e redução dessa probabilidade na sua ausência (Sério et al., 2002). O processo de discriminação se refere, então, ao estabelecimento de uma classe de respostas que ocorre na presença de uma determinada classe de estímulos ( $S^{\mathrm{D}}$ ou $\left.\mathrm{S}+\right)$, que sinaliza a presença do estímulo reforçador, e não ocorre (ou ocorre em menor frequência) na ausência desse estímulo ou na presença de um estímulo que sinalize a ausência do reforço ( $S^{\Delta}$ ou $S$-). Dismoor (1950) argumenta ainda que os estímulos discriminativos podem exercer a mesma função que um reforçador condicionado, tendo em vista a similaridade das curvas de extinção quando o $S^{\mathrm{D}}$ é apresentado antes ou depois da resposta.

O controle exercido pelo estímulo antecedente tem grande relevância na Análise do Comportamento pelo fato do operante ocorrer, quase que necessariamente, sob controle desse tipo de estímulo, pois poucas são as respostas que não tem relação com as circunstâncias externas. Skinner (1953/2003) afirma que a importância da discriminação "em uma análise teórica, assim como no controle prático do comportamento, é óbvia: quando uma discriminação já foi estabelecida, podemos alterar a probabilidade de uma resposta instantaneamente pela apresentação ou remoção de um estímulo discriminativo" (p. 119). 
Embora de grande importância, o controle de estímulo não tem sido um dos focos principais de pesquisa dentro da Análise do Comportamento, tendo sempre maior destaque nos estudos a relação entre o comportamento e suas consequências (Sidman, 2008). A maior parte das investigações a respeito do controle discriminativo data das décadas de 50 e 60 .

Experimentos realizados principalmente nesta época demonstram um padrão diferenciado de resposta (medido em taxa de resposta, número de resposta ou latência) na presença do $S^{D}$ ou $S^{\Delta}$ (Notterman \& Block, 1960). Estes (1948) e Morse e Skinner (1958) demonstraram ainda que o estabelecimento de contingência entre o $S^{D}$ e o estímulo reforçador é suficiente para fazer com que o $\mathrm{S}^{\mathrm{D}}$ controle uma resposta condicionada posteriormente.

Os dois tipos de procedimento geralmente utilizados para o treino discriminativo são: discriminação sucessiva, quando o $S^{D}$ e $\quad$ o $S^{\Delta}$ são apresentados sucessivamente; ou discriminação simultânea, quando o $S^{\mathrm{D}}$ e o $S^{\Delta}$ são apresentados ao mesmo tempo e o organismo deve responder ao $\mathrm{S}^{\mathrm{D}}$, mas não ao $\mathrm{S}^{\Delta}$ (Sério et al., 2002). Alguns procedimentos realizam apenas o treino em $S^{D}$ (e não um treino diferencial entre estímulos). Nesses procedimentos geralmente se observa picos mais baixos durante o teste de discriminação. É comum também o uso de esquemas intermitentes de reforçamento durante o treino (Honing \& Urcuioli, 1981).

Nos estudos iniciais um procedimento utilizado para mensurar o controle de estímulos eram testes em extinção, onde os estímulos treinados eram apresentados sem que houvesse consequências diferenciais entre eles, e era, então, observada a taxa de resposta emitida na presença de cada estímulo (Dismoor, 1950; Morse \& Skinner, 1958). Outra maneira de se mensurar o nível de discriminação entre estímulos é a partir de testes de generalização, que se caracterizam pela apresentação de uma série de estímulos semelhantes aos estímulos 
treinados, sem que nenhum deles esteja relacionado a alguma consequências, e observa-se como a taxa de resposta de distribui ao longo do contínuo (Honing \& Urcuioli, 1981).

O fenômeno da generalização, que é derivado do estabelecimento da discriminação operante e/ou respondente, tem sido o maior interesse dos experimentos que envolvem treino de discriminação. Foi a partir do estudo realizado por Guttman e Kalish (1956) que a generalização passou a ser investigada empiricamente, deixando de ser apenas uma entidade teórica.

O processo de generalização, observado a partir do estabelecimento da discriminação, se refere a "extensão" de uma resposta treinada na presença do estímulo discriminativo para estímulos semelhantes a ele, ou seja, a ocorrência da resposta também na presença de outros estímulos que apresente algum tipo de semelhança com o estímulo previamente treinado. Dessa forma, estabelece-se um gradiente de generalização que se caracteriza pelo aumento da resposta em função do aumento da semelhança com o estímulo treinado, e diminuição da resposta em função da diminuição dessa semelhança (Dinsmoor, 1995).

Três tipos de gradiente de generalização são comumente observados na literatura. $\mathrm{O}$ primeiro tipo é a generalização do estímulo positivo, que ocorre quando o treino de discriminação é feito de maneira que a presença do estímulo sinaliza o reforço $(\mathrm{S}+)$ e a ausência do estímulo sinaliza ausência de reforço (S-). Assim, o gradiente de generalização geralmente tem o seu pico no $\mathrm{S}+$ treinado e o número de respostas diminui à medida que os estímulos apresentados se diferenciam do $\mathrm{S}+$. O segundo tipo de gradiente é o de generalização do estímulo negativo ou generalização da extinção, que ocorre quando a ausência do estímulo é o que sinaliza a presença do reforço. Nesse caso, a curva do gradiente de generalização se dá no formato inverso (geralmente de $\mathrm{U}$ ou V), e o indivíduo responde mais quanto mais diferente for o estímulo apresentado do estímulo relacionado com a ausência do reforço. O terceiro tipo é o gradiente proveniente do treino que combina o 
estímulo positivo e negativo dentro de um mesmo espectro, como por exemplo, tons diferentes de luz ou de som funcionando como cada um dos estímulos (Dismoor, 1995).

É importante notar que a discriminação e a generalização funcionam como dois lados de um mesmo processo e, assim, a distribuição das respostas em um teste de generalização funciona como uma medida de discriminação. Respostas que se distribuem de maneira muito homogênea ao longo de um espectro de estímulos sinalizam que a discriminação não foi bem estabelecida (Dismoor, 1995). Quando a discriminação é bem estabelecida, entretanto, geralmente se observa o pico de respostas na presença do estímulo treinado (S+). Porém, em procedimentos que utilizam $\mathrm{S}+$ e $\mathrm{S}$ - dentro de um mesmo espectro é comum se observar um deslocamento do pico para um estímulo que esteja mais distante do S- (Honing \& Urcuioli, 1981).

O gradiente de generalização que resulta de uma discriminação entre reforço e extinção, geralmente, difere de um gradiente resultante do treino entre dois estímulos sinalizando diferentes esquemas. Isso se deve ao fato de que a extinção, além do seu efeito inibitório, exerce também um efeito excitatório sobre a taxa de resposta na presença do estímulo discriminativo, aumentando-a (Reynolds, 1961a). Dessa forma, outro efeito observado nesse tipo de treino, além do deslocamento do pico do gradiente de generalização, é o efeito de contraste comportamental (Terrace, 1966b).

O efeito de contraste se refere à alteração da taxa de resposta durante a apresentação de um estímulo em função de alterações feitas no esquema de reforçamento associado a um estímulo diferente, sendo essa mudança na taxa de resposta durante o primeiro estímulo na direção oposta à taxa produzida pelo estímulo no qual o esquema foi alterado (Reynolds, 1961b). O contraste pode ser positivo, quando em um esquema múltiplo se observa um aumento da taxa de resposta no componente que é mantido constante em função de uma "piora" nas condições de reforçamento do componente variável, ou negativo, quando a taxa 
de resposta no componente constante diminui em função de uma "melhora" nas condições de reforçamento do componente variável (McSweeney, Ettinger \& Norman, 1981). O contraste ocorre tipicamente, mas não apenas, durante a formação de discriminação entre dois estímulos, sendo um deles correlacionado com a ausência de reforço.

Killeen (2014) cita alguns tipos de contraste que podem ser observados: 1) transitório ou local, quando o contraste é inicial, sendo observado no começo do treino ou sob condições de discriminação pobre, podendo desaparecer com treinos extensos; 2) antecipatório ou terminal, quando o contraste ocorre no fim do treino ou em condições de boa discriminação; 3) contraste molar, quando o efeito de contraste é observado na taxa média do componente e; 4) contraste dimensional, quando o controle de estímulos se dá ao logo de uma dimensão, sendo observado através de modulações ao longo dessa dimensão.

Reynolds (1961b) realizou uma série de experimentos a fim de verificar que tipos de manipulações no segundo componente aumentam a taxa no primeiro componente e quais manipulações mantém essa taxa constante, usando um múltiplo onde o primeiro componente era sempre um esquema de intervalo variável (VI) e manipulando os esquemas do segundo componente. No segundo componente foram utilizados VI, timeout, extinção e reforço diferencial de outros comportamentos (DRO, adicionado ao timeout ou a extinção). Foi observado efeito de contraste quando o segundo componente era um timeout ou extinção, porém, não foram observadas mudanças significativas no primeiro componente quando o segundo era programado com um DRO. Assim, o contraste na presença de um estímulo parece ser eliminado pelo reforçamento do "não responder" na presença de outro estímulo. Isso pode se dever ao fato de que é a ausência de reforço no segundo componente, e não uma baixa taxa de resposta, responsável pelo contraste. A alteração da taxa de reforço no segundo componente altera a taxa de reforço relativa do primeiro componente, gerando assim o efeito observado. 
Terrace (1966b) afirma que o contraste observado no treino com reforço e extinção se dá em função do tipo e extensão do treino de discriminação e argumenta que em um treino sem erros, nem o efeito de contraste, nem o deslocamento do pico do gradiente são observados. A fim de investigar essa hipótese, foram conduzidos dois experimentos. No Experimento 1 foi realizado um longo treino de discriminação sucessiva (60 sessões) em que o S+ sinalizava um esquema VI 1 minuto, enquanto o S- sinalizava extinção e ficava em vigor por 1 minuto, a menos que alguma resposta fosse emitida (cada resposta emitida atrasava o fim da apresentação do S- por 30 segundos). O que se observou é que, embora o efeito de contraste tenha ocorrido para todos os sujeitos, ele desapareceu nas últimas sessões do treino, onde a taxa retornou aos níveis da linha da base. Além disso, não foi observado o deslocamento do pico do gradiente de generalização, que se deu no valor do S+. No Experimento 2 foi utilizado o mesmo procedimento do experimento anterior, alterando apenas o valor do S- (encurtando a distância entre $\mathrm{S}+$ e $\mathrm{S}$-) e aumentando o número de testes de generalização que ocorreram após 15, 30, 45 e 60 sessões. Observou-se mudanças no pico do gradiente de generalização com o aumento do número de sessões de treino. Embora nos primeiros testes o deslocamento tenha sido observado, no último teste de generalização, assim como no Experimento 1, o pico se localizou no valor do $\mathrm{S}+$. O padrão de contraste no Experimento 2 foi o mesmo observado no Experimento 1. Esses dados demonstram que tanto o contraste comportamental, quanto o deslocamento do pico do gradiente de generalização, parecem ser efeitos transitórios.

Além da extensão do treino ter efeito sobre o contraste conforme demonstrado por Terrace (1966b), Killeen (2014) afirma que a duração do componente parece também alterar a maneira como o contraste se distribui, principalmente no tipo de contraste transitório. Dois efeitos podem ser observados em função do aumento da duração do componente para esse tipo de contraste: o aumento do contraste inicial e a diminuição da média do contraste no 
componente constante. Se a duração do componente constante em relação à taxa de reforçamento for mantida, e a duração do componente variável em relação à taxa de reforçamento for aumentada, o contraste deve aumentar. Porém, se a duração do componente constante aumentar, enquanto for mantida a duração do componente variável, o contraste deve diminuir, em função da sua maior ocorrência no início do componente. Se a duração dos dois componentes variarem juntas, o contraste diminui com o aumento da duração.

Para Killeen (2014) todos os tipos de contraste podem ser explicados a partir da teoria de competição de respostas. O autor defende a noção de que o contraste ocorre em função de comportamentos adjuntivos que competem com a resposta reforçada, reduzindo a sua taxa no componente. Quando o componente variável "permite" a maior ocorrência desses comportamentos adjuntivos, como por exemplo em esquemas de extinção, a resposta alvo fica mais livre da competição no esquema que é mantido constante (para mais teorias descritivas e explicativas a respeito do contraste comportamental, ver McSweeney et al. 1981).

\section{Controle de estímulos em contextos sociais}

Skinner (1953/2003) afirma que não só estímulos físicos podem atuar no controle do comportamento, mas também estímulos sociais, observados no que ele chama de episódio social. Assim, o comportamento de uma outra pessoa, ou a sua mera presença, podem funcionar de maneira a sinalizar as consequências disponíveis, alterando a probabilidade de emissão de determinados comportamentos por uma segunda pessoa. $\mathrm{O}$ autor afirma ainda que "um estímulo social, como qualquer outro estímulo, torna-se importante no controle do comportamento por causa das contingências em que se encaixa” (p. 330).

Os estímulos sociais exercem uma função de regulação do comportamento de modo a aumentar a sua eficácia. Skinner (1953/2003) argumenta a relevância do controle exercido 
pelo comportamento de outra pessoa em situações de cooperação, que requerem ação combinada dos dois indivíduos, sendo assim necessário que o comportamento de um fique sob controle do comportamento do outro.

Alguns estudos com animais, fazendo uso de estímulos discriminativos sociais foram realizados. Husted e McKenna (1966) demonstraram controle de estímulos utilizando a presença ou ausência de outro rato como $S^{D}$ e $S^{\Delta}$, respectivamente. Hake, Donalson e Hyten (1983) argumentam, entretanto, que a unidade básica de análise em uma interação social é o controle discriminativo por comportamentos específicos de outro animal e propõem uma série de experimentos a fim de demonstrar o controle discriminativo do comportamento de um indivíduo pelo comportamento de outro indivíduo (líder). Os autores citam ainda alguns experimentos que foram conduzidos para investigar o comportamento de um indivíduo tendo função de controle de estímulos, como por exemplo, Miller e Dollard (1941), Skinner (1962), Danson e Creed (1970) e Millard (1979) (revisões sobre o tema em Hake \& Olvera, 1978 e Hake \& Vukelich, 1972).

Schmitt e Marwell (1968) realizaram um experimento sobre cooperação com humanos investigando o papel do controle discriminativo na coordenação dos comportamentos dos indivíduos. Foram utilizados dois procedimentos com diferentes exigências de intervalos entre as respostas dos dois indivíduos e foram manipuladas a presença ou ausência de estímulos antecedentes que sinalizavam tanto emissão de resposta por um dos participantes (o comportamento de um participante acendia uma luz que funcionava como $S^{D}$ para a emissão da resposta pelo segundo participante) quanto o período de timeout onde nenhuma resposta seria reforçada $\left(\mathrm{S}^{\Delta}\right)$. O que se observou foi que com a exigência de intervalos muito curtos (0,5 segundos), a presença ou ausência dos estímulos não exerceu controle, tendo em vista que as respostas ocorriam quase que simultaneamente (indício de que o comportamento de um não estava sendo controlado pelo comportamento do outro). Porém, com o aumento na 
exigência do intervalo entre as respostas (3 segundos), observou-se que a ausência do estímulo que funcionava como $S^{D}$ reduziu as respostas de cooperação a quase zero, indicando assim o papel que estímulos antecedentes podem exercer na coordenação entre comportamentos de dois ou mais indivíduos.

O estudo de Schmitt e Marwell (1968) está entre os primeiros estudos de cooperação com humanos dentro da Análise do Comportamento e ainda faz uso da tríplice contingência como ferramenta de análise. O tipo de controle de estímulos manipulado nesses estudos, em analogia à metacontingência, se refere ao controle de estímulo que ocorre ainda no nível do entrelaçamento, ou seja, o comportamento de um atuando como $\mathrm{S}^{\mathrm{D}}$ para o comportamento do outro (nível operante). Considerando que a metacontingência é utilizada para analisar o processo de seleção do produto agregado (Todorov, 2012a), ainda faltam estudos que demonstrem a função exercida por estímulos antecedentes que sinalizam o reforço do produto agregado (que é diferente dos estímulos providos pelos comportamentos entrelaçados dos indivíduos envolvidos). O único estudo que trabalha com esse tipo de manipulação, conhecido até o momento, é o da Vieira (2010), que investiga o papel que estímulos antecedentes podem exercer na metacontingência.

O experimento de Vieira (2010) segue a tradição de experimentos na área de metacontingência utilizando o procedimento de Pereira (2008), que trabalha com a inserção coordenada de números, manipulando consequências individuais e culturais e troca de gerações. Os estímulos antecedentes manipulados eram a cor de fundo da tela do programa. Os resultados indicam estabelecimento de controle discriminativo, porém, não há sistematicidade nos dados de generalização.

Soares, Cabral, Leite e Tourinho (2014) também realizaram um experimento que envolvia controle de estímulos, embora não envolvesse a manipulação de estímulos antecedentes e treino discriminativo, como o trabalho de Vieira (2010). Soares et al. (2014) 
trabalharam com diferentes exigências de produto agregado (e entrelaçamento) que demandava, assim, a discriminação, pelos participantes, dos estímulos que cumpriam ou não as exigências de cada metacontingência em vigor. Utilizando também o procedimento de matriz, semelhante ao de Vichi (2004), os autores tentaram observar o estabelecimento de diferentes padrões de entrelaçamento e formação de produto agregado em um delineamento de reversão que manipulava tanto consequências individuais quanto culturais. Os autores observaram que houve "a seleção de duas práticas culturais distintas" (Soares et al., 2014, p. 44), porém, os dados não são sistemáticos. Embora tenha sido demonstrada tanto a seleção operante, quanto a seleção cultural, a partir do uso de diferentes consequências, não há evidências de que ocorreu o processo de discriminação das exigências em vigor.

Em função da importância relatada que os estímulos discriminativos têm sobre a emissão do comportamento e na tentativa de estudar os processos básicos envolvidos no terceiro nível de seleção, de maneira análoga ao estudo do operante, o presente estudo tem como objetivo investigar os efeitos do processo de discriminação simples na metacontingência. Busca-se analisar se o terceiro nível de seleção respeita os mesmos padrões observados nos estudos de discriminação operante, que se referem ao segundo nível de seleção, (aumento da probabilidade de resposta na presença do $S^{D}$ e diminuição da probabilidade na presença do $S^{\Delta}$ ) a partir de um procedimento de discriminação sucessiva. Este esforço se justifica pelo pequeno número de trabalhos que explorem o papel dos estímulos discriminativos na metacontingência, apesar da relevância já demonstrada destes estímulos no comportamento operante.

Foi utilizado o mesmo procedimento de Vasconcelos (2014). Este procedimento apresenta a vantagem de ser um procedimento simplificado, que respeita aos critérios de uma metacontingência, e possibilita um maior controle experimental, tendo em vista que são manipuladas as variáveis apenas no nível cultural, sem a manipulação contingências 
operantes atuando no nível individual. O experimento foi composto por quatro fases: Linha de Base, Treino de Discriminação, Teste de Discriminação e Teste de Generalização. Com esse estudo se pretendeu: 1) testar um procedimento que faz uso da metacontingência enquanto unidade de análise, no qual, diferentemente dos estudos que vem sendo realizados na área, os tipos de consequência (individual ou cultural) não foram manipulados, não havendo consequências individuais para as respostas; 2) testar a viabilidade de um treino de discriminação a partir unicamente de reforço social; 3) aplicar o procedimento de discriminação sobre o responder de mais de um indivíduo simultaneamente e; 4) observar os efeitos do treino de discriminação em um teste de generalização.

Foram manipulados os estímulos antecedentes relacionados à presença $\left(S^{D}\right)$ ou ausência de reforço $\left(S^{\Delta}\right)$ a fim de que fosse observado o seu efeito sobre a formação do produto agregado. 


\section{MÉTODO}

\section{Participantes}

Participaram da pesquisa 22 adultos entre 18 e 29 anos (média das idades de 20,04 anos), estudantes de graduação e pós-graduação da Universidade de Brasília. Os participantes foram selecionados por conveniência, sendo convidados através de avisos em sala de aula. Aqueles que aceitaram participar preencheram uma ficha de identificação (Anexo 1) informando os horários disponíveis para participação na atividade e email para contato. A seleção dos participantes foi feita a partir da compatibilidade de horários para a formação de duplas. Após a formação das duplas, os participantes foram notificados e solicitados a comparecer no local do experimento em data e horário especificados, onde, antes do início do procedimento receberam e assinaram o Termo de Consentimento Livre e Esclarecido (Anexo 2).

Ao todo, 11 duplas participaram do experimento, porém, apenas os dados de 8 duplas foram analisados. Três delas foram descartadas da análise de dados por problemas durante o procedimento $^{1}$.

O projeto foi submetido ao CEP/IH Brasil para análise.

\section{Materiais e instrumentos}

A coleta de dados foi realizada no Laboratório de Pesquisa em Avaliação e Medidas (Labpam), localizado no Instituto de Psicologia da Universidade de Brasília, onde se encontrava uma mesa grande com um notebook, duas cadeiras (dispostas lado a lado na

${ }^{1}$ A retirada das duplas da análise de dados se deveu a motivos como: travamento do programa durante a execução do experimento; desistência de um dos participantes deixando apenas um responsável por executar a tarefa da dupla, ou; desistência de ambos os participantes que pararam de responder e "aguardaram" o fim da sessão. 
lateral da mesa) e, em separado, uma cadeira para o experimentador. O experimentador esteve presente em todas as sessões e, após a entrega das instruções, se mantinha sentado numa cadeira na lateral da mesa onde se encontravam os participantes.

Para a realização da atividade foi utilizado um notebook Samsung, processador Core i3, 2.10GHz, 2GB de RAM, com sistema Microsoft Windows 7 Home Basic. O notebook foi equipado com o software "Xadrez" (Todorov \& Vianney, 2013), que permitia a movimentação das peças por um tabuleiro virtual de tamanho 8x8 células (Fig. 1 e Fig. 2).

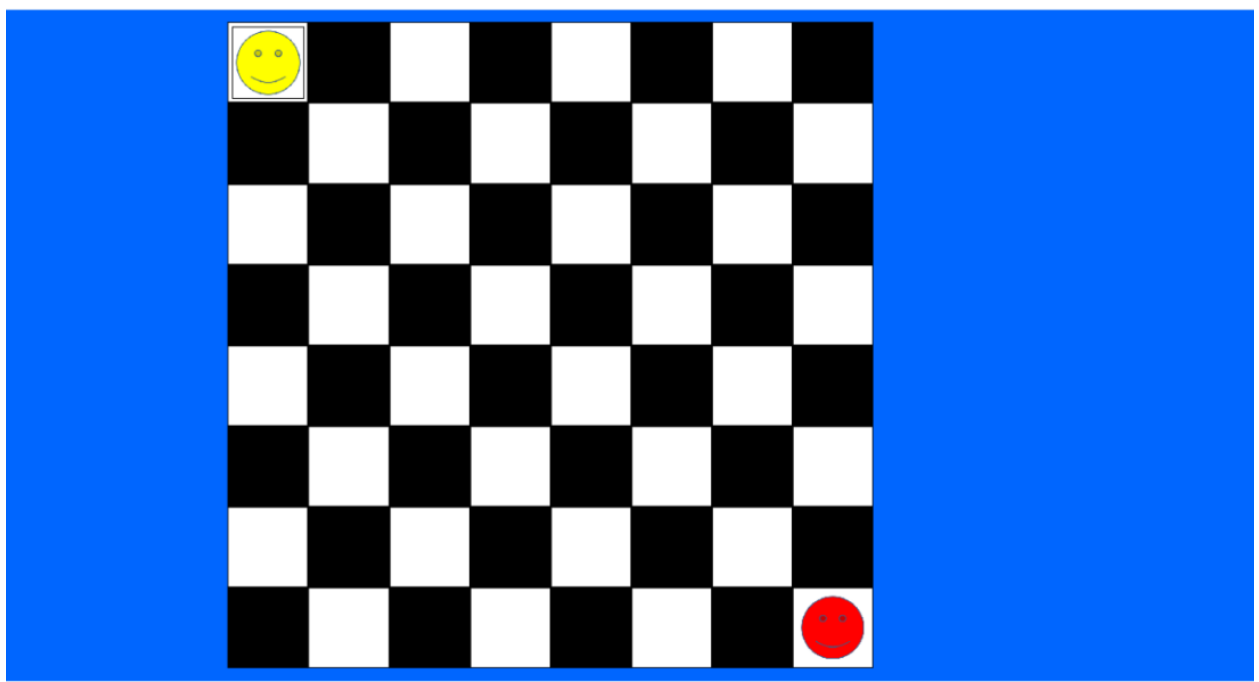

Figura 1. Tabuleiro na condição $S^{\mathrm{D}}$.

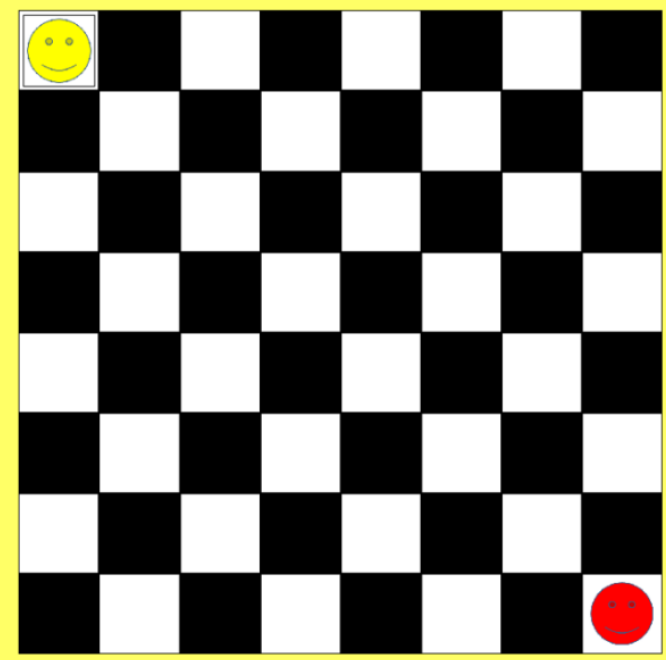

Figura 2. Tabuleiro na condição $S^{\Delta}$. 
O software foi programado com parâmetros específicos em quatro fases. Os resultados gerados pelo software foram: o número de tentativas, acertos, erros, número de movimentos, local de ocorrência de cada movimento, tempo de duração de cada movimento, tempo de duração de cada apresentação de estímulo e o tempo decorrido de cada fase.

\section{Procedimento}

Cada dupla participou da atividade uma única vez. Ao entrarem na sala de coleta, receberam e assinaram o TCLE. Em seguida, foi entregue uma ficha, para a dupla, com as seguintes instruções:

Olá!

A partir de agora, vocês realizarão uma atividade juntos. Este jogo tem um caráter cooperativo, portanto, vocês estão jogando juntos e não um contra o outro. Cada jogador terá uma "carinha" no tabuleiro e deverá movimentá-la através de clicks no mouse. Para movê-la, basta dar um toque em cima da célula que deverá receber a peça. Cada “carinha” move-se fazendo um ' $L$ ' em qualquer direção. $O$ movimento em 'L' move a peça por 3 casas em cada jogada (por exemplo, uma casa para frente e duas para o lado). Uma rodada começa com a peça de cada jogador localizada nos extremos do tabuleiro. O jogador que ficar com a peça do extremo superior esquerdo sempre começa as rodadas. Os jogadores movem suas peças alternadamente. O objetivo do jogo é que as peças se encontrem no momento certo. As peças não ocupam a mesma célula e o encontro pode ocorrer em qualquer posição (horizontal, vertical ou diagonal). Ao final de cada rodada, 
caso ela tenha sido bem sucedida, vocês receberão a mensagem: "PARABÉNS! O objetivo foi alcançado!". Clique na mensagem para começar uma nova rodada.

A duração do experimento dependerá do desempenho de vocês. O programa informará quando o jogo chegar ao fim. Mas, vocês podem encerrar o experimento a qualquer momento, caso desejem.

Alguma dúvida? Em caso de dúvidas, releiam as instruções! Vocês podem consulta-las em qualquer momento durante a atividade. É permitido conversar durante as rodadas do jogo, mas se mantenham atentos à tarefa.

Decidam que ficará com cada peça do tabuleiro. Cada jogador deve continuar com a mesma peça até o fim do jogo.

Quando estiverem prontos, cliquem na tela para começar.

Não foram dadas instruções verbais adicionais e em caso de dúvidas os participantes eram instruídos a ler a ficha novamente. Após a compreensão das instruções os participantes davam início à atividade. A atividade consistia na movimentação das peças pelo tabuleiro virtual, sendo cada participante responsável pelo movimento de uma das peças. O objetivo era que as peças ficassem em casas adjacentes (lado a lado, uma em cima da outra ou diagonalmente) e isso caracterizava um encontro.

O experimento foi composto de quatro fases, descritas a seguir.

Linha de Base: nesta fase encontro das peças podia ocorrer em qualquer ponto do tabuleiro e todos os encontros eram reforçados com a apresentação da mensagem “PARABÉNS! O objetivo foi alcançado!”. 
A fase se encerrava após 10 encontros. A cor da tela permanecia azul durante toda a fase. Esta primeira fase foi utilizada como base de comparação para as fases subsequentes de treino e teste de discriminação.

Treino de Discriminação: nessa fase foi realizado um treino discriminativo. Esta fase manipulava o estímulo antecedente contingente à disponibilidade do reforço. As cores de fundo do tabuleiro funcionavam como $S^{D}$ e $S^{\Delta}$ (Fig. 1 e Fig. 2). A cor de fundo azul funcionava como $\mathrm{S}^{\mathrm{D}}$ (comprimento de onda da cor: $484 \mathrm{~nm}$ ), ou seja, os encontros das peças em qualquer ponto do tabuleiro ocorridos na presença da cor azul eram seguidos de reforço (mensagem "PARABÉNS! O objetivo foi alcançado!”). Já a cor de fundo amarela funcionava como $\mathrm{S}^{\Delta}$ (comprimento de onda da cor: $582 \mathrm{~nm}$ ), ou seja, aqui o encontro não gerava consequência (mensagem de parabéns) e após a sua ocorrência as peças voltavam às suas posições iniciais.

A cada tentativa completada na presença do $S^{D}$, a cor da tela mudava para $S^{\Delta}$. O critério para encerramento da apresentação do $S^{\Delta}$ se dava por tempo de inatividade, sendo considerado como inatividade um intervalo de tempo sem que houvesse sem produção de produto agregado (ou seja, sem realização do encontro), porém, o movimento das peças era permitido. O critério inicial era de 10 segundos na ausência de produto agregado que progredia de 5 em 5 segundos até que os participantes permanecessem sem se encontrar durante 60 segundos consecutivos. A cada cumprimento do tempo de inatividade exigido durante o $S^{\Delta}$, o tabuleiro voltava para a condição do $S^{\mathrm{D}}$, e assim a apresentação dos estímulos se deu de maneira alternada.

Foi utilizada a progressão do tempo, pelo alto número de desistência quando as primeiras exposições à extinção eram muito longas. 
A fase se encerrava quando os participantes permaneciam 60 segundos inativos durante 3 apresentações do $S^{\Delta}$. A contagem do tempo era reiniciada sempre que as peças se encontravam na condição do $S^{\Delta}$.

Teste de Discriminação: nessa fase era realizado um teste discriminativo. A fase ocorria de maneira semelhante à Treino de Discriminação, exceto que $\mathrm{S}^{\mathrm{D}}$ e $\mathrm{S}^{\Delta}$ eram apresentados sucessivamente, durante intervalos de 60 segundos.

Nesta fase, os encontros ocorridos na presença do $S^{\mathrm{D}}$ continuavam a ser seguidos de reforço, enquanto os encontros ocorridos na presença do $S^{\Delta}$ continuavam em extinção.

A fase era encerrada após 10 minutos (5 apresentações alternadas de cada estímulo) e se caracterizava enquanto teste pela alteração do critério de duração da apresentação dos estímulos em relação à fase anterior. Aqui, o $S^{D}$ se mantinha em vigor por 1 minuto e não mais até a ocorrência de um encontro. Já o $\mathrm{S}^{\Delta}$ também se mantinha em vigor pelo mesmo período de tempo, não sendo mais atrasado pela ocorrência de encontros. Ambos os estímulos permaneciam em vigor por um intervalo de tempo, independente da ocorrência ou não de encontros na presença de cada um deles.

Teste de Generalização: essa fase era caracterizada pela apresentação de 7 cores. Além das cores que sinalizavam $S^{\mathrm{D}}$ e $\mathrm{S}^{\Delta}$, outras cinco cores foram utilizadas com os seguintes comprimentos de onda: 566nm, 533nm, 500nm, 4688nm e $451 \mathrm{~nm}$. Não havia consequências para o responder durante a apresentação de nenhuma das cores, se dando toda a fase em extinção. As cores foram apresentadas uma única vez, durante intervalos de 120 segundos, e foram apresentadas na seguinte ordem: $582 \mathrm{~nm}\left(\mathrm{~S}^{\Delta}\right), 566 \mathrm{~nm}, 533 \mathrm{~nm}, 500 \mathrm{~nm}, 484 \mathrm{~nm}\left(\mathrm{~S}^{\mathrm{D}}\right)$, $468 \mathrm{~nm}$ e $451 \mathrm{~nm}$.

Após o fim do Teste de Generalização o programa apresentava a mensagem "Fim!" indicando o término do experimento. 


\section{Análise de Dados}

O que se considerou enquanto resposta no presente trabalho foi o encontro entre as peças no tabuleiro, que caracterizava a formação do Produto Agregado (PA). Na análise dos dados a medida principal utilizada neste experimento foi a taxa de produto agregado (PA/tempo) em cada uma das fases, ao longo de toda a sessão experimental. Outras medidas observadas em cada fase foram: número de encontros realizados em cada condição, número de movimentos realizados em cada tentativa e o índice de dispersão (tanto das células do tabuleiro utilizadas para a ocorrência do PA, quanto da localização dos PAs).

O cálculo da taxa de produto agregado e do número de movimentos foi feito por tentativa, sendo que o critério de tentativa variou entre as condições. Na Linha de Base cada encontro caracterizava uma tentativa. $O$ mesmo para a condição de $S^{D}$ no Treino de Discriminação. Já para a condição de $\mathrm{S}^{\Delta}$ no Treino, considerou-se como tentativa cada apresentação do estímulo (que se encerrava após x segundos sem ocorrência de encontro). Nas condições de Teste de Discriminação e de Generalização também se considerou cada apresentação do estímulo como uma tentativa. No Teste de Discriminação cada estímulo permanecia em vigor por 1 minuto, enquanto no Teste de Generalização cada estímulo permanecia em vigor por 2 minutos.

O índice de dispersão das células foi calculado a partir a relação entre o número de células utilizadas e o número de células possíveis (por exemplo, na Linha de Base eram 10 encontros, logo, 20 células possíveis de serem utilizadas; assim o cálculo foi feito pelo número de células diferentes utilizadas/número de células possíveis de serem utilizadas, no caso, 20). Já a dispersão da localização do Produto Agregado foi calculada a partir da localização das células por encontro, a fim de analisar se todos os encontros ocorriam no mesmo local, ou se haviam uma variação na localização. Assim, calculou-se o número de encontros em diferentes posições/o número de encontros totais ocorridos. 
Para cada fase foram realizadas comparações intradupla e comparações entre duplas. Com as comparações intradupla pretendeu-se observar os possíveis efeitos diferenciados esperados para cada fase e entre cada estímulo $\left(\mathrm{S}^{\mathrm{D}}\right.$ e $\left.\mathrm{S}^{\Delta}\right)$. Já com as comparações entre duplas esperou-se descrever tendências gerais observadas em cada fase, funcionando como replicações diretas. 


\section{RESULTADOS}

A média de tempo das sessões foi de $58^{\prime} 37^{\prime \prime}$, com a média da duração da Linha de Base de 7'48'' e a média de duração do Treino de Discriminação de 26'47' (as fases de Teste de Discriminação e Generalização tinham tempo fixo sendo 10 e 14 minutos, respectivamente).

A Fig. 3 mostra a análise da taxa de PA para as três primeiras fases do experimento. Observou-se que, apesar da variabilidade nas taxas, a ocorrência do PA foi estabelecida na Linha de Base. Para cinco das oito duplas (D3, D7, D8, D9 e D11) observou-se um aumento sistemático nas taxas de PA do começo ao final da fase. Para D11, observa-se um grande aumento da taxa no final da Linha de Base, entretanto, essa alta taxa não se mantém de maneira constante nas fases seguintes.

Na fase de Treino pode-se observar que, de maneira geral, a taxa durante as apresentações de $S^{\mathrm{D}}$ foram mais altas do que durante a apresentação do $S^{\Delta}$. Com a introdução da condição de $\mathrm{S}^{\Delta}$ pode-se observar, ainda, um aumento da taxa em $\mathrm{S}^{\mathrm{D}}$ em relação à Linha de Base para seis das oito duplas (D3, D5, D7, D8, D9, D10), caracterizando assim o efeito de contraste comportamental. Para as duplas D3 e D10 o efeito de contraste é mais evidente nas tentativas finais da fase de Treino. Para D6, embora se observe alguns pontos em que a taxa é maior do que a obtida na linha de base, não há um aumento sistemático da taxa de uma condição para outra. Já para D11, se observa um grande aumento na taxa nas tentativas finais da Linha de Base, mas esse aumento não se mantém, nem se amplia, durante o treino.

Em relação à taxa em $S^{\Delta}$ na fase de Treino, pode-se observar que, para todas as duplas, a taxa de PA na primeira apresentação desse estímulo é 0. Isso provavelmente se deveu a uma característica do procedimento, pois a exigência de inatividade nessa primeira apresentação era de 10 segundos sem ocorrência de encontros. Como essa exigência era 

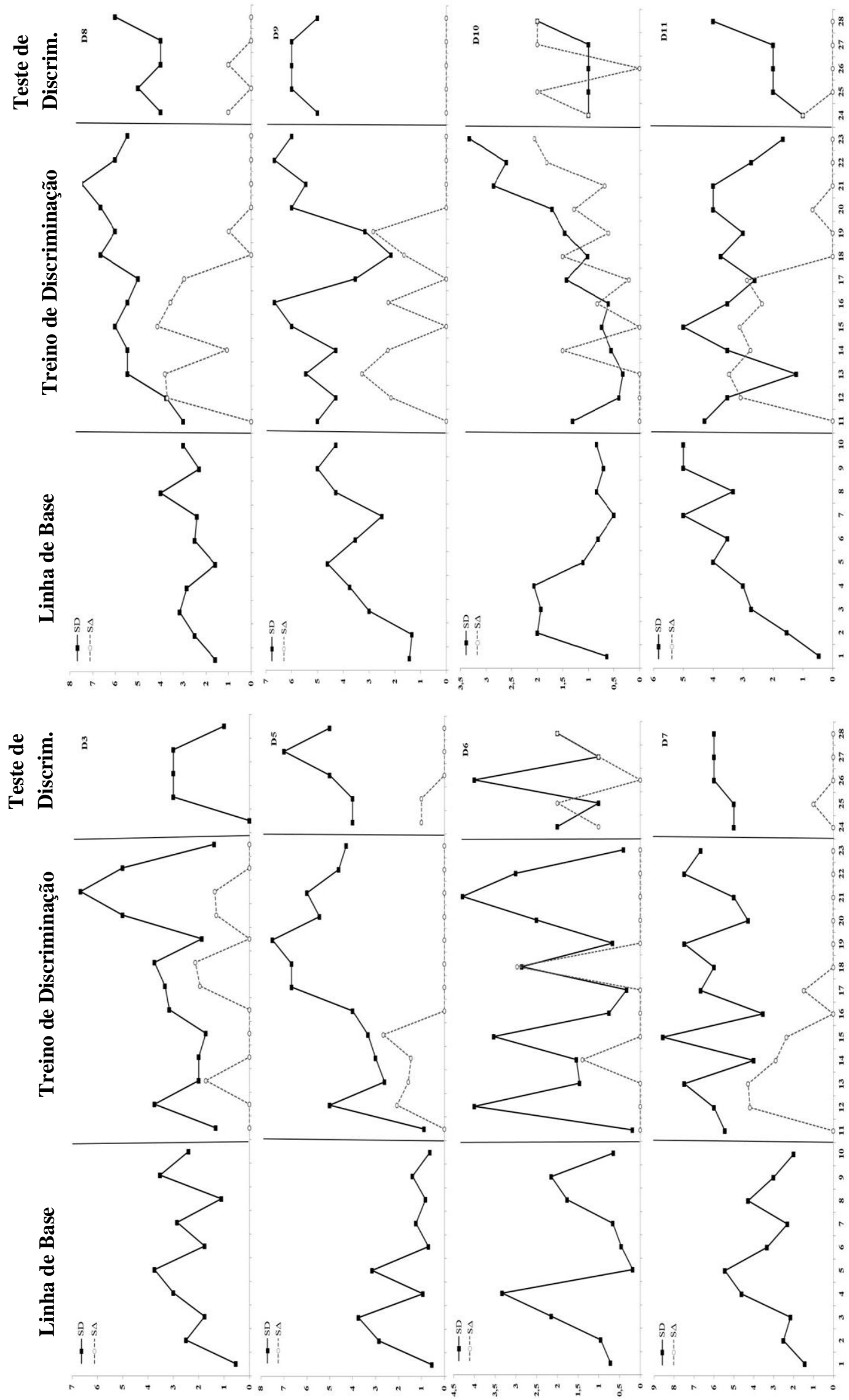

: 
menor do que o tempo médio para a ocorrência de um encontro é possível que nessa primeira apresentação todas as duplas tenham alcançado o critério por acaso (o estímulo se encerrou antes que houvesse tempo suficiente para as peças se encontrarem). Embora haja um aumento das taxas nas tentativas seguintes em $\mathrm{S}^{\Delta}$, é observado um decréscimo sistemático ao longo da fase, para todas as duplas, exceto D10. A diferenciação entre as taxas de PA indicam o estabelecimento do controle discriminativo pelos diferentes estímulos apresentados.

Na fase de Teste de Discriminação observa-se que se manteve a maior taxa na presença do $\mathrm{S}^{\mathrm{D}}$ em relação ao $\mathrm{S}^{\Delta}$. As duplas D3, D7, D8, D10 e D11 apresentaram uma queda na taxa em $\mathrm{S}^{\mathrm{D}}$ em relação à fase anterior. Isso pode ser devido ao fato de que na fase de treino a presença do $S^{\mathrm{D}}$ sinalizava a ocorrência de apenas um encontro, que era seguido do reforço e então se passava para o $S^{\Delta}$. Já na fase de Teste, a duração de apresentação do $S^{\mathrm{D}}$ obedecia a um critério de tempo e não de razão. Para as duplas D3, D5, D6, D7, D8 e D11 observou-se também um aumento, mesmo que transitório, da taxa em $\mathrm{S}^{\Delta}$. Apesar das flutuações nas taxas, para seis das oito duplas (D3, D5, D7, D8, D9 e D11) observou-se taxas bem diferenciadas entre os dois estímulos, evidenciando assim o estabelecimento da discriminação. Dessa forma, houve mais ocorrência de PA na condição associada ao reforço do que na condição associada a extinção.

A dupla D10, além de não apresentar um decréscimo na taxa de PA na presença do $S^{\Delta}$ durante o Treino, também não apresenta padrão de taxa diferenciada durante o Teste de Discriminação. Isso pode ter se devido ao fato de que essa dupla trabalhou a uma taxa muito baixa desde o início da sessão (são as menores taxas dentre todas as duplas). Dessa forma, os critérios estabelecidos para o $\mathrm{S}^{\Delta}$ na fase de Treino podem ter sido alcançados por acaso (tempo médio entre as ocorrências dos encontros maiores do que 60 segundos, cumprindo assim o critério, sem necessariamente terem discriminado as condições). 


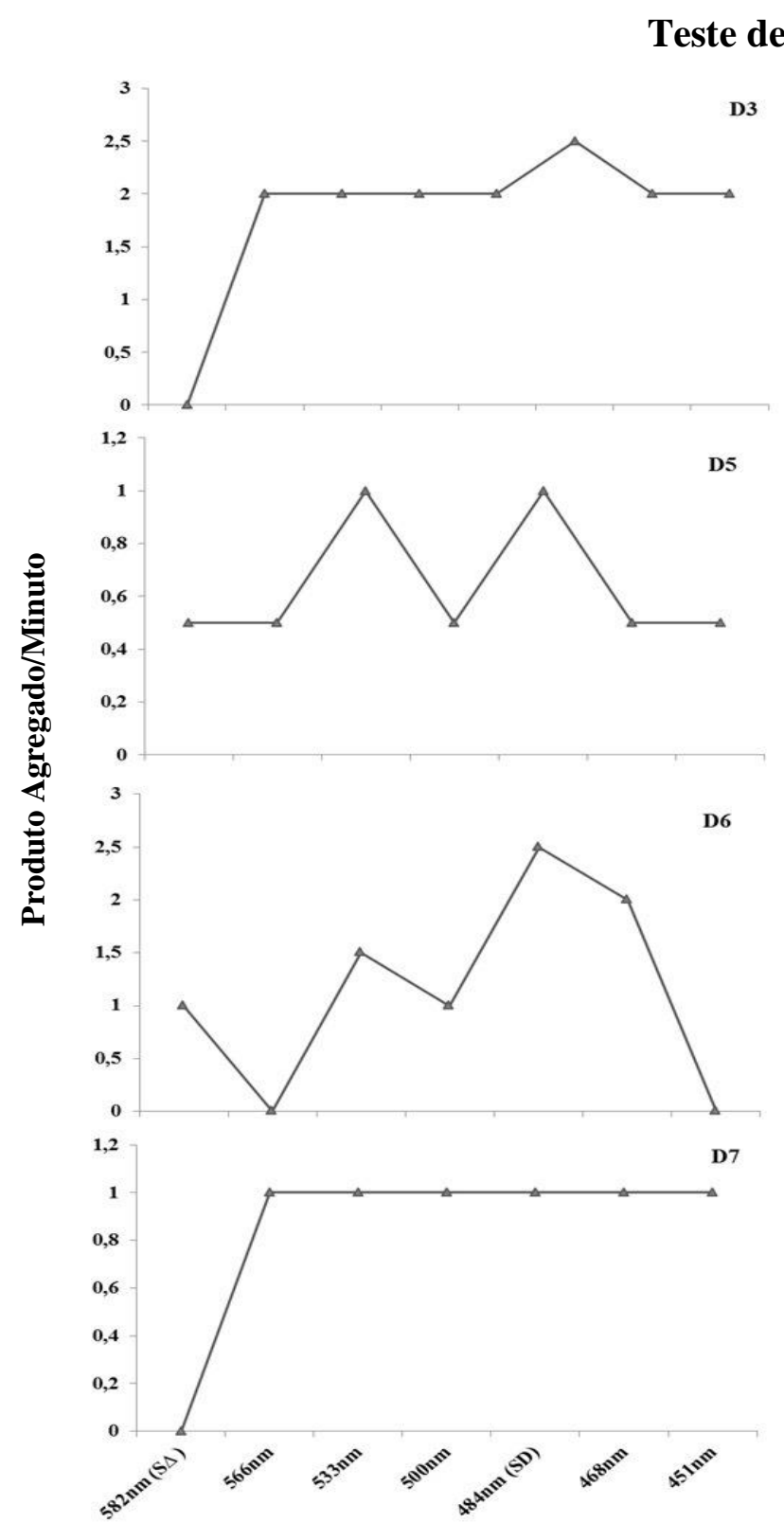

\section{Generalização}

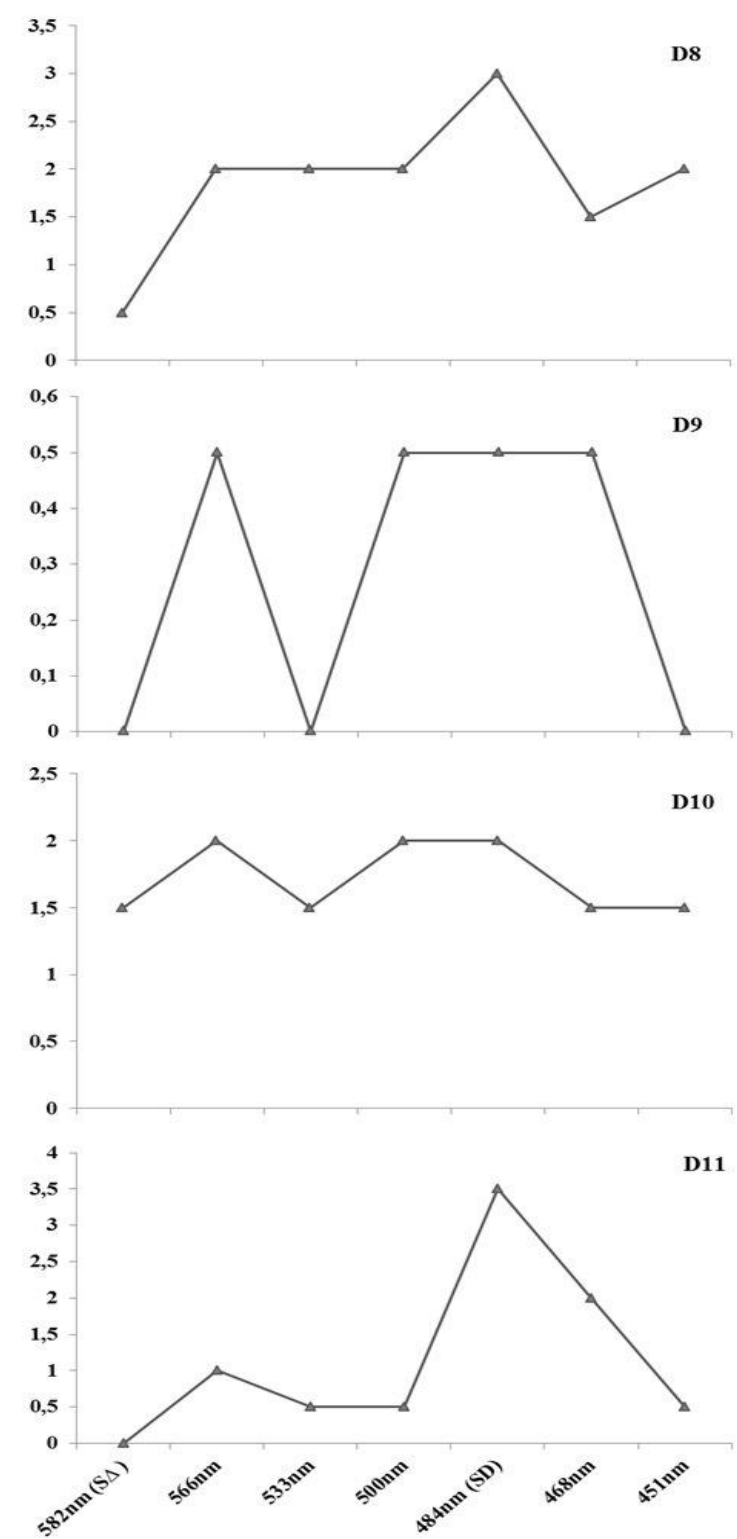

Estímulos

Figura 4. Taxa de produto agregado por minuto ao longo da fase de Teste de Generalização. Note que o eixo y varia para cada dupla.

Já os dados no Teste de Generalização (Fig. 4) não demonstram muita sistematicidade. Apenas quatro das oito duplas (D3, D6, D8 e D11) apresentam uma taxa de PA mais alta na presença do $S^{\mathrm{D}}$, evidenciando o pico do gradiente de generalização previsto na literatura (porém, para nenhuma das duplas a taxa foi menor na presença desse estímulo em relação aos demais). Não se observou o deslocamento do pico para nenhuma das duplas. 
Embora as duplas D5, D7, e D9 apresentem taxas bastante diferenciadas entre os estímulos no Teste de Discriminação, no Teste de Generalização a distribuição das respostas se dá de maneira relativamente achatada (distribuição das respostas de maneira regular entre os diversos estímulos), o que questiona o estabelecimento da discriminação para essas duplas.

Observou-se uma correlação entre o tempo de duração do Treino e o padrão de distribuição de respostas no Teste de Generalização. As duplas que apresentaram o pico de PA na presença do $S^{D}$ durante o Teste de Generalização foram aquelas para as quais a fase de Treino teve duração maior do que a média $\left(28^{\prime 2} 25^{\prime \prime}\right.$ para D3, 27'17'” para D6, 36'22'" para D8 e 28'13'" para D11). D10 também obteve um tempo de Treino acima da média, embora não demonstre o padrão das demais duplas no Teste de Generalização.

Uma segunda análise realizada foi em relação aos números de movimentos (Fig. 5). O número de movimentos foi calculado também por tentativas, e assim como no cálculo das taxas, foram consideradas tentativas cada encontro na Linha de Base e na condição $S^{D}$ no Treino e cada apresentação de estímulo para a condição $\mathrm{S}^{\Delta}$ no Treino e para ambos os estímulos no Teste. Os movimentos na fase do Teste de Generalização não foram analisados.

Tal análise demonstrou que o número de movimentos se manteve constante durante as apresentações do $S^{D}$, porém, variou consideravelmente durante as apresentações do $S^{\Delta}$, sendo geralmente maior na presença desse estímulo. $\mathrm{O}$ aumento do número de movimentos em $\mathrm{S}^{\mathrm{D}}$ durante o Teste se deveu ao fato de que cada tentativa nessa fase tinha duração de um minuto, logo, ocorriam mais de um encontro, diferente das fases antecedentes em que cada encontro era considerado uma tentativa. A constância do número de movimentos em $\mathrm{S}^{\mathrm{D}}$ é um indício da estereotipia gerada pelo reforço, pois as duplas emitiam, em média, o mesmo número de movimentos até o encontro na presença do estímulo correlacionado ao reforço, mais variavam mais na presença do estímulo correlacionado à extinção. 

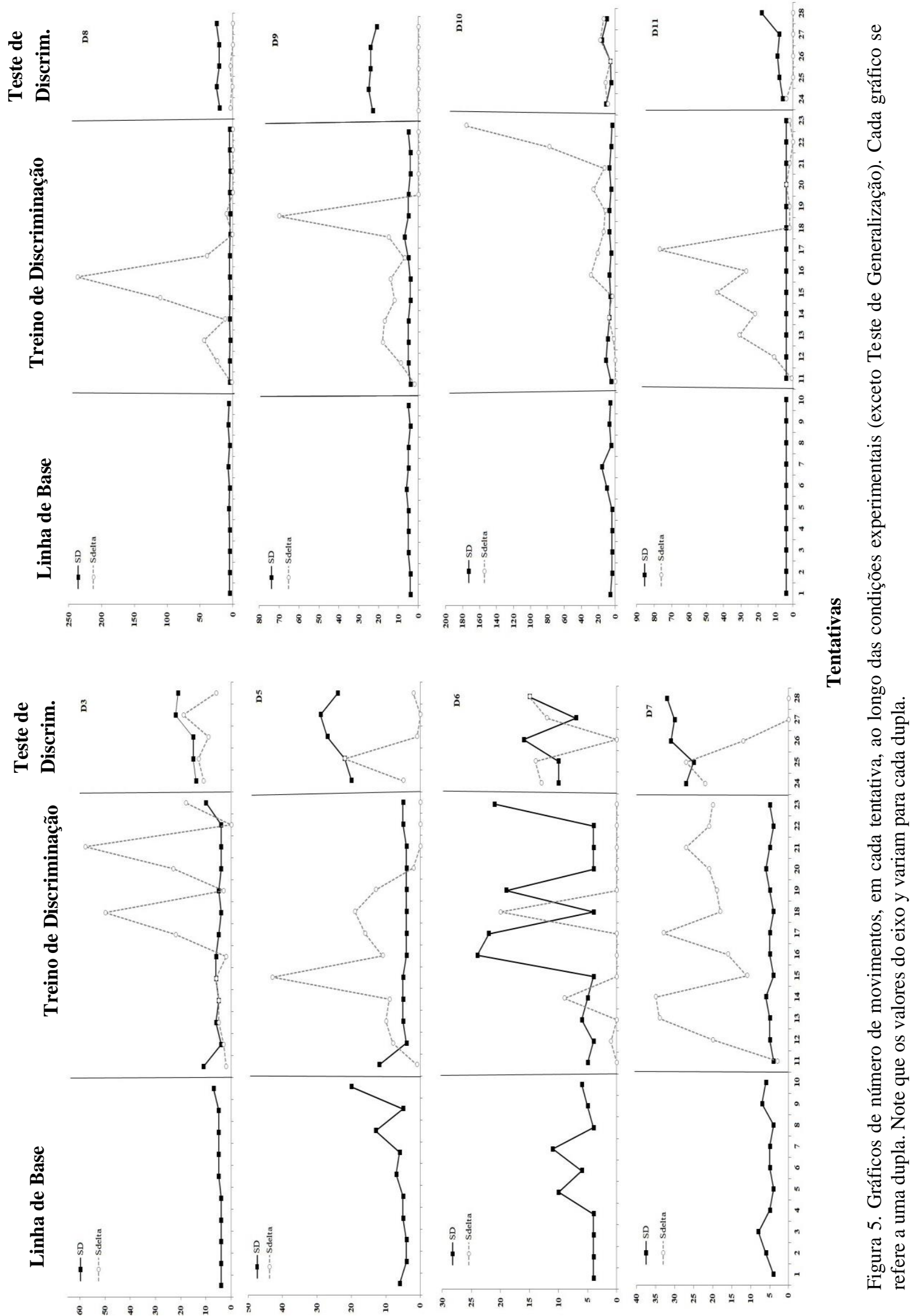

Número de movimentos 
A dupla D6, entretanto, apresentou bastante variabilidade no número de movimentos, principalmente na presença do $S^{D}$, evidenciando assim que não houve aqui o padrão de estereotipia geralmente observado. Já a dupla D10, embora, não tenha apresentado indícios de discriminação (Fig. 1), emitiu, como as demais duplas, números regulares de movimento na presença do $S^{\mathrm{D}}$.

De modo geral, essa análise permitiu perceber que diferentes padrões de comportamento foram estabelecidos pela contingência de extinção em vigor durante a apresentação do $S^{\Delta}$ na fase de treino: para algumas duplas se observou a extinção de qualquer tipo de movimento enquanto o estímulo estava em vigor (D5, D6, D8, D9); para outras duplas se observou a extinção da formação dos PAs e o desenvolvimento de outros padrões de comportamento, como por exemplo, o comportamento de "passear" pelo tabuleiro (D3, D7, D10 e D11). Dessa forma, há evidências de que, para algumas duplas o $\mathrm{S}^{\Delta}$ funcionou como uma contingência de extinção, enquanto para outras duplas funcionou como um DRO (tendo como reforço o retorno $\mathrm{S}^{\mathrm{D}}$ ).

Uma última variável analisada foi o índice de dispersão (Fig. 4), a fim de se observar diferenças no nível de variabilidade das respostas na presença de cada estímulo. O índice de dispersão foi calculado, para cada dupla, de duas maneiras: dispersão no uso das células do tabuleiro (calculado a partir da proporção de células utilizadas durante o encontro dentre o número de células possíveis) e dispersão na localização do produto agregado (calculado a partir da proporção de encontros com diferentes localizações dentre os encontros ocorridos).

Os dois cálculos do índice de dispersão apresentaram o mesmo padrão, sistematicamente, para todas as duplas (exceto para D9): ao longo das condições o índice de dispersão diminuiu na presença do $\mathrm{S}^{\mathrm{D}}$, indicando a estereotipia gerada pelo reforço, e aumentou na presença do $S^{\Delta}$, possivelmente em função da variabilidade induzida pela extinção. A ausência de dispersão durante $S^{\Delta}$ no Teste de Discriminação para a dupla D9 se 


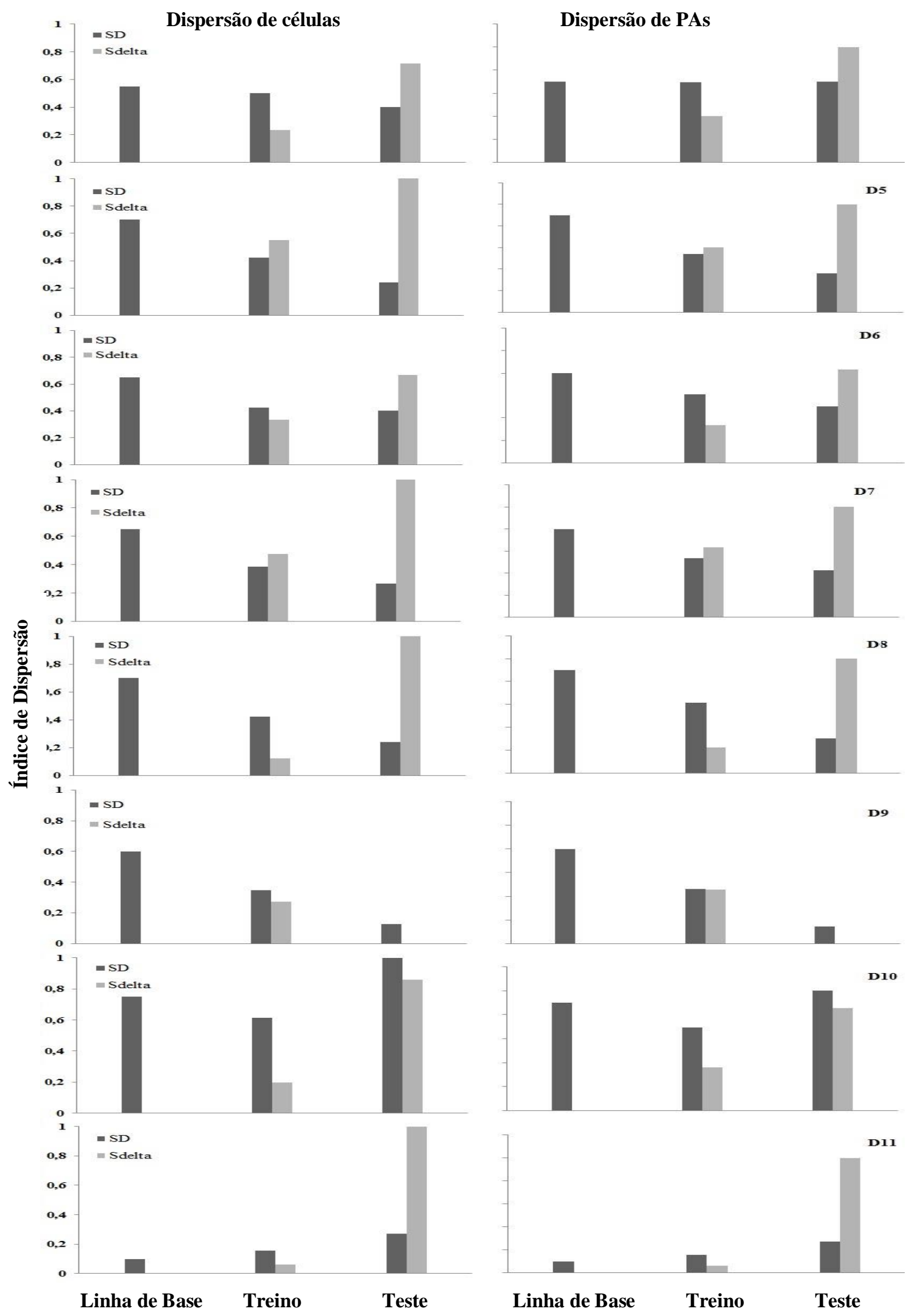

Figura 6. Na coluna da esquerda, gráficos indicando a dispersão no uso das células ao longo das condições para cada dupla. Na coluna da direita, gráficos indicando a dispersão da localização do Produto Agregado ao longo das condições para cada dupla. 
deveu ao fato de que a dupla havia parado de responder a esse estímulo desde as quatro últimas tentativas durante a fase de Treino, não emitindo nenhuma resposta para esse estímulo durante o Teste. 


\section{DISCUSSÃO}

O objetivo principal do presente trabalho foi averiguar a possibilidade de estabelecimento de controle de estímulos para a ocorrência de Produtos Agregados, que envolvem comportamentos entrelaçados de mais de um indivíduo ao mesmo tempo, a partir de um procedimento simplificado. Pretendeu-se analisar se, assim como o comportamento operante, a ocorrência de Produtos Agregados é sensível aos estímulos antecedentes que sinalizam a presença ou ausência de reforço, e se, sendo sensível a essas variáveis, haveria um padrão diferenciado na taxa de ocorrência desses PAs na presença de um ou outro estímulo. Além disso, pretendeu-se também analisar a possibilidade de estabelecimento da ocorrência do Produto Agregado e o estabelecimento de um processo de discriminação sobre o responder de mais de um indivíduo simultaneamente a partir unicamente de reforço cultural.

O primeiro ponto a ser observado é que a utilização de um procedimento simplificado, que atende à definição de metacontingência, por envolver contingências comportamentais entrelaçadas (comportamento de um indivíduo funcionando como estímulo antecedente e consequente para o comportamento de um segundo indivíduo, e vice-versa) que geram um Produto Agregado selecionado por uma consequência cultural, se mostrou eficiente em demonstrar o estabelecimento da ocorrência do PA sem envolver modelagem de comportamentos individuais e sem utilizar consequências diferenciais para cada indivíduo, assim como foi observado por Vasconcelos (2014). A formação de PA ao longo de toda a sessão experimental demonstra, então, a viabilidade da utilização de um procedimento mais simples para investigação de fenômenos que ocorrem em um terceiro nível de seleção.

Apesar da variabilidade observada nos dados, há indícios de que o controle discriminativo foi estabelecido em função das taxas diferenciais de PA na presença de ambos 
os estímulos. O padrão observado durante o Teste de Discriminação é um indicador do controle discriminativo exercido por cada estímulo, muito embora não se observe sistematicidade para todas as duplas durante o Teste de Generalização. Os indicativos do estabelecimento de discriminação nesse estudo corroboram os resultados de Vieira (2010) que também observou controle pelos estímulos antecedentes na formação de Produtos Agregados. Assim como no presente estudo, Vieira (2010) também não observou sistematicidade no teste de generalização.

É importante notar, entretanto, algumas diferenças metodológicas entre os estudos. A primeira delas é que o presente estudo trabalhou com um procedimento simplificado no qual participavam apenas dois participantes por vez, atuando simultaneamente no mesmo computador, sem haver manipulação de outras consequências além daquela contingente à formação do produto agregado. Já o experimento de Vieira trabalhou com um procedimento mais complexo, do qual participavam mais de dois participantes por vez, trabalhando em telas diferentes, que envolvia a manipulação de consequências individuais e culturais, além de trocas de gerações.

O presente estudo também trabalhou com a manipulação de um único aspecto do estímulo antecedente (cor de fundo da tela) que sinalizava a presença ou ausência do reforço para a formação do produto agregado, enquanto Vieira (2010) manipulou mais de um aspecto das condições antecedentes (cor de fundo da tela e ordem das cores dos quadrantes de cada participante), que sinalizavam diferentes exigências de produto agregado, não havendo assim uma contingência de extinção.

Nos resultados do presente trabalho pode-se observar também que, embora haja uma taxa de produto agregado diferenciadas entre os estímulos durante a fase de Teste de Discriminação, nota-se uma pequena diminuição na taxa nesta fase, em relação ao Treino, para algumas duplas (D7, D8, D9, D10 e D11). Essa diferença pode se dever à alteração na 
duração dos estímulos. No treino, a mudança de $S^{D}$ para $S^{\Delta}$ se dava a cada encontro e havia uma contingência de atraso da duração de $S^{\Delta}$ contingente a cada ocorrência de PA. Já na fase de Teste há uma modificação na contingência associada a apresentação de cada estímulo, estando esses em vigor por intervalos fixos de tempo (1 minuto cada um). Dessa forma, cada encontro ocorrido na presença do $S^{D}$ não sinaliza mais o início do $S^{\Delta}$. Essa mudança na contingência de apresentação dos estímulos de uma fase para outra pode ser apontado como um fator que pode ter atrapalhado ou modificado a maneira como a discriminação foi estabelecida.

Uma possível explicação para a assistematicidade dos dados de generalização no presente trabalho pode ter sido, então, essa mudança na duração dos estímulos de uma fase para a outra, atuando como uma variável estranha no estabelecimento da discriminação. Outro fator que pode também ter afetado o estabelecimento da discriminação, foi a alternância entre estímulos. Por exemplo, no treino cada encontro ocorrido na presença do $\mathrm{S}^{\mathrm{D}}$ sinalizava não apenas a apresentação do reforço, como também a mudança para a condição de $S^{\Delta}$. Assim, a presença de um estímulo sinalizava, necessariamente, a apresentação do outro estímulo em seguida, já que os estímulos eram apresentados sucessivamente e não de maneira aleatória. No Teste de Generalização, a maneira e a ordem na qual as cores foram apresentadas também podem ter contribuído para a distribuição das respostas, tendo em vista que quando o $S^{\mathrm{D}}$ era apresentado nessa fase, a dupla já estava há muitos minutos em extinção. Outra possível explicação pode ter sido a extensão da sessão, de forma que as fases de treino e teste de discriminação podem não ter sido longas o suficiente para gerar um padrão bem estabelecido de discriminação.

Embora o efeito de deslocamento do pico de gradiente de generalização, conforme previsto na literatura, não tenha sido observado, foi possível observar o efeito de contraste comportamental quando ocorreu a introdução do $S^{\Delta}$ na fase de Treino, corroborando a 
literatura sobre treinos de discriminação (Reynolds, 1971a e 1971b). Os dados estão de acordo com aqueles demonstrados por Reynolds (1971b), que indicam o efeito contraste relacionado à ausência de reforço no componente variável.

Terrace (1966b), porém, afirma que o efeito de contraste, assim como de deslocamento do pico, é função do tipo e extensão do treino de discriminação. Dessa forma, a realização de um treino mais longo neste experimento, além de aumentar o nível de discriminação demonstrado no Teste de Generalização, poderia também fazer desaparecer o efeito de contraste observado. Apenas para a dupla D3 o efeito de contraste foi mais evidente nas últimas tentativas da fase de Treino. Para todas as outras que apresentaram o efeito, este foi evidente já nas primeiras tentativas. Porém, a duração desta fase foi muito curta para permitir esse tipo de avaliação.

O contraste comportamental observado neste trabalho se encaixa no que Killeen (2014) chama de contraste transitório, por ser observado já na fase inicial do treino. O autor afirma, ainda, que a duração dos componentes pode ter efeito sobre esse tipo de contraste. Isso pode explicar, também, algumas das diferenças observadas nas taxas de produto agregado entre as fases de Treino e Teste de Discriminação. Durante a fase de Treino, a duração de cada $\mathrm{S}^{\mathrm{D}}$ era o equivalente a duração para ocorrência do encontro. Já a duração do $\mathrm{S}^{\Delta}$ era função do tempo exigido sem ocorrência do PA (sendo o intervalo atrasado a cada ocorrência deste), e sendo essa exigência de 1 minuto nas três últimas apresentações do estímulo durante a fase de treino. Com exceção da dupla D10, para todas as outras duplas não houve encontro nas últimas apresentações do $S^{\Delta}$, dessa forma, a duração do estímulo foi de 1 minuto, de acordo com o estabelecido pelo critério. Na fase de Teste, cada estímulo passou a ficar em vigor pelo intervalo fixo de 1 minuto, logo, a duração do $S^{\mathrm{D}}$ passou a ser maior do que era na fase de Treino (pois, cada PA ocorria em um tempo médio menor do que 1 minuto), porém, a duração do $\mathrm{S}^{\Delta}$ se manteve a mesma das tentativas finais durante o treino. 
Assim, houve uma mudança na duração de um dos componentes (componente correlacionado ao reforço), mas não houve mudança da duração do segundo componente (componente correlacionado à extinção). Segundo Killeen (2014) o aumento da duração do componente correlacionado ao reforço, enquanto o segundo componente se manteve constante, pode ter como um dos efeitos a diminuição do contraste, tal como observado no presente trabalho, em função da queda na taxa de PA durante o Teste de Discriminação (e.g. Shimp \& Wheatley, 1971; Todorov, 1972).

Os dados em relação aos números de movimentos e índices de dispersão, também corroboram os efeitos, já observados no nível operante, de estereotipia gerada pelo reforçamento e variabilidade gerada pela extinção. Esses efeitos já haviam sido observados no experimento de Vasconcelos (2014).

Algumas modificações nas manipulações feitas neste experimento, entretanto, podem ser sugeridas a fim de se melhorar o controle experimental e buscar dados mais sistemáticos, que demonstrem de maneira mais clara o estabelecimento do controle dos estímulos antecedentes para a ocorrência de produtos agregados. Uma primeira possibilidade seria aumentar a duração das fases de treino e teste de discriminação a fim de observar tanto um padrão mais claro de discriminação no teste de generalização, quanto a manutenção ou desaparecimento do efeito de contraste (conforme sugerido por Terrace, 1966). Manter a duração dos componentes constantes durante as fases também pode ser uma forma de evitar possíveis enfraquecimentos no processo de discriminação, além de possibilitar uma avaliação mais precisa do efeito de contraste, sem variáveis estranhas que possam confundir os resultados. Trabalhar com esquemas de reforçamento intermitentes associados ao $\mathrm{S}^{\mathrm{D}}$, como sugerido na literatura (Honing \& Urcuioli, 1981) pode tornar o responder mais resistente à extinção durante o teste de generalização, levando assim a padrões mais claros de discriminação durante esta fase. Pode-se, também, modificar a ordem de apresentação dos 
estímulos, para que a alternância não se confunda com o estabelecimento da discriminação. Uma outra maneira de acessar o estabelecimento da discriminação seria através de um procedimento que trabalhasse com reversão de estímulos. Mudanças nas contingências sinalizadas pelos estímulos também poderiam ser feitas, trabalhando-se com diferentes critérios de produto agregado, como por exemplo, diferentes cores sinalizando diferentes localizações requeridas do produto agregado, ao invés de se trabalhar com contingências de reforçamento e extinção associadas a cada estímulo.

De maneira geral, o presente estudo demonstra a possibilidade de se trabalhar com um procedimento mais simplificado que atende às definições do conceito de metacontingência, além de dar indícios de que, assim como no nível operante, o controle exercido pelos estímulos antecedentes parece ter relevância também quando se fala em um terceiro nível de seleção (Houmanfar \& Rodrigues, 2006). Faz-se importante, então, avanços nas investigações sobre os processos básicos envolvidos no terceiro nível de seleção, a fim de se observar se os princípios estabelecidos pelos estudos do comportamento operante também se aplicam a este nível.

De grande relevância também é a discussão acerca da definição do conceito, a fim de se chegar a uma definição comum e, assim, dissolver os problemas tanto conceituais, quanto metodológicos, encarados pela área atualmente. Utilizando-se uma definição precisa e unificada, caminha-se para a resolução de alguns problemas empíricos, facilitando o estabelecimento de um procedimento experimental básico que uniformize os dados e torne-os comparáveis, uma vez que o uso de diferentes metodologias e manipulação de diferentes variáveis dificulta a replicação dos dados e a busca de explicação para as possíveis diferenças encontradas entre os estudos. 


\section{REFERÊNCIAS}

Azrin, N. H., \& Lindsley, O. R. (1956). Reinforcement of cooperation between children. Journal of Abnormal and Social Psychology, 52, 100-102.

Bullerjhann, P.B. (2009). Análogos experimentais de fenômenos sociais: os efeitos das conseqüências culturais. Dissertação de mestrado. Pontifícia Universidade Católica de São Paulo, São Paulo, SP, Brasil.

Caldas, R.A. (2009). Análogos experimentais de seleção e extinção de metacontingências. Dissertação de mestrado. Pontifícia Universidade Católica de São Paulo, São Paulo, SP, Brasil.

Catania, C.A. (1999). Aprendizagem: comportamento, linguagem e cognição. Trad. Deisy das Graça de Souza. Porto Alegre: Artmed.

Danson, C., \& Creed, T. (1970). Rate of response as a visual social stimulus. Journal of the Experimental Analysis of Behavior, 13, 233-242.

Dinsmoor, J. A. (1950). A quantitative comparison of the discriminative and reinforcing functions of a stimulus. Journal of Experimental Psychology, 40(4), 458-472.

Dinsmoor, J. A. (1995). Stimulus control: Part I. The Behavior Analyst, 18(1), 51-68.

Estes, W. K. (1948). Discriminative conditioning II. Effects of a Pavlovian conditioned stimulus upon a subsequently established operant response. Journal of Experimental Psychology, 38, 173-177.

Glenn, S. S. (1986). Metacontingencies in Walden Two. Behavior Analysis and Social Action, 5, 2-8.

Glenn, S. S. (1988). Contingencies and metacontingencies: Toward a synthesis of behavior analysis and cultural materialism. The Behavior Analyst, 11, 161-179. 
Glenn, S. S. (2004). Individual behavior, culture, and social change. The Behavior Analyst, 27,133-151.

Glenn, S. S., \& Malott, M. 2004). Complexity and selection: Implications for organizational change. Behavior and Social Issues, 13, 89-106.

Guttman, N., \& Kalish, H. J. (1956). Discriminability and stimulus generalization. Journal of the Experimental Analysis of Behavior, 51(1), 79-88.

Hake, D. F., \& Olvera, D. (1978). Cooperation, competition, and related social phenomena. In A. C. Catania \& T. A. Brigham (Eds.), Handbook of applied behavior Analysis: Social and instructional processes. New York: Irvington, 208-245.

Hake, D. F., Olvera, D., \& Bell, J. C. (1975). Switching from competition to sharing or cooperation at large response requirements: Competition requires more responding. Journal of the Experimental Analysis of Behavior, 24(3), 343-354.

Hake, D. F., Donaldson, T., \& Hyten, C. (1983). Analysis of discriminative control by social behavioral stimuli. Journal of the Experimental Analysis of Behavior, 39(1), 7-23.

Hake, D. F., \& Vukelich, R. (1972). A classification and review of cooperation procedures. Journal of the Experimental Analysis of Behavior, 18(2), 333-343.

Honing, W. K., \& Urcuioli, P. J. (1981). The legacy of Guttman and Kalish (1956): 25 years of research on stimulus generalization. Journal of the Experimental Analysis of Behavior, $36(3), 405-445$.

Houmanfar, R., \& Rodrigues, N. J. (2006). The metacontingency and the behavior contingency: Points of contact and departure. Behavior and Social Issues. 15, 13-30.

Husted, J. R., \& McKenna, F. S. (1966). The use of rats as discriminative stimuli. Journal of the Experimental Analysis of Behavior, 9, 677-679.

Killeen, P. R. (2014). A theory of behavioral constrast. Journal of the Experimental Analysis of Behavior, 102(3), 363-390. 
Lamal, P. A. (1991). Three metacontingencies in the pre-perestroika Soviet Union. Behavior and Social Issues, 1(1), 75-90.

Lamal, P. A., \& Greenspoon, J. (1992). Congressional metacontingencies. Behavioral and Social Issues, 2, 71-81.

Malott, M., \& Glenn, S. S. (2006). Targets of intervention in cultural and behavioral change. Behavior and Social Issues, 15, 31-56.

Martone, R. C., \& Todorov, J. C. (2007). O desenvolvimento do conceito de metacontingência. Revista Brasileira de Análise do Comportamento, 3, 181-190.

Martone, R. C. (2008). Efeitos de conseqüências externas e de mudanças na constituição do grupo sobre a distribuição dos ganhos em uma metacontingência experimental. Tese de doutorado. Universidade de Brasília, Brasília, DF, Brasil.

McSweeney, F. K., Ettinger, R. H., \& Norman, W. D. (1981). Three versions of the additive theories of behavioral contrast. Journal of the Experimental Analysis of Behavior, 36, 285-297.

Millard, W. J. (1979). Stimulus properties of conspecific behavior. Journal of the Experimental Analysis of Behavior, 32, 283-296.

Miller, N. E., \& Dollard, J. (1941). Social learning and imitation. New Haven: Yale University Press.

Morse, W. H., \& Skinner, B. F. (1958). Some factors involved in the stimulus control of operant behavior. Journal of the Experimental Analysis of Behavior, 1(1), 103-107.

Notterman, J. M., \& Block, A. H. Note on response differentiation during a simple discrimination. Journal of the Experimental Analysis of Behavior, 3(4), 289-291.

Pereira, J.M.C. (2008). Investigação experimental de metacontingências: separação do produto agregado e da consequência individual. Dissertação de mestrado. Pontifícia Universidade Católica de São Paulo, São Paulo, SP, Brasil. 
Rakos, R. F. (1991). Perestroika, glasnost, and international cooperation: a behavior analysis. Behavior and Social Issues, 1(1), 91-100.

Reynolds, G. S. (1961a). Behavioral contrast. Journal of the Experimental Analysis of Behavior, 4(1), 57-71.

Reynolds, G. S. (1961b). Contrast, generalization and the process of discriminations. Journal of the Experimental Analysis of Behavior, 4(4), 289-294.

Sampaio, A. A. S., \& Andery, M. A. P. A. (2010). Comportamento social, produção agregada e prática cultural: uma análise comportamental de fenômenos sociais. Psicologia: Teoria e Pesquisa, 26(1), 183-192.

Schimitt, D. R. (1976). Some conditions affecting the choice to cooperate or compete. Journal of the Experimental Analysis of Behavior, 25(2), 165-178.

Schimitt, D. R., \& Marwell, G. (1968). Stimulus control in the experimental study of cooperation. Journal of the Experimental Analysis of Behavior, 11(5), 571-574.

Schimitt, D. R., \& Marwell, G. (1971a). Taking and the disruption of cooperation. Journal of the Experimental Analysis of Behavior, 15(3), 405-412.

Schimitt, D. R., \& Marwell, G. (1971b). Avoidance of risk as a determinant of cooperation. Journal of the Experimental Analysis of Behavior, 16(3), 367-374.

Sénéchal-Machado, V., \& Todorov, J. C. (2008). A travessia na faixa de pedestre em Brasília (DF/ Brasil): exemplo de uma intervenção cultural. Revista Brasileira de análise do Comportamento, 4(2), 191-204.

Sério, T. M. A. P., Andery, M. A., Gioia, P. S., \& Micheletto, N. (2002). Os conceitos de discriminação e generalização. In: T. M. A. P. Sério, M. A. Andery, P. S. Gioia, \& N. Micheletto. In Controle de estímulos e comportamento operante (Capítulo 1, pp. 7-24) . São Paulo: EDUC. 
Shimp, C. P., \& Wheatley, K. L. (1971). Matching to relative reinforcement frequency in multiple schedules with a short component duration. Journal of the Experimental Analysis of Behavior, 15, 205-210.

Sidman, M. (2008). Reflections on stimulus control. The Behavior Analyst, 31(2), 127-135.

Skinner, B. F. (1962). Two "synthetic social relations." Journal of the Experimental Analysis of Behavior, 5, 531-533.

Skinner, B. F. (1981). Selection by consequences. Science, 213, 501-514

Skinner, B. F. (2003). Ciência e comportamento humano (11 ${ }^{\mathrm{a}}$ ed.). Trad. de J. C. Todorov e R. Azzi. São Paulo: Martins Fontes. (Obra original publicada em 1953).

Soares, P. F., Cabral, P. A., Leite, F. L., \& Tourinho, E. Z. (2014). Efeitos de consequências culturais sobre a seleção e manutenção de duas práticas culturais alternadas. Revista Brasileira De Análise Do Comportamento, 8(1).37-46.

Terrace, H. S. (1966a) Stimulus control. In W. K. Honig (Ed.), Operant behavior. New York: Appleton-Century-Crofts.

Terrace, H. S. (1966b). Behavioral contrast and the peak shift: Effects of extended discrimination training. Journal of the Experimental Analysis of Behavior, 9(6), 613-617.

Todorov, J. C. (1972). Component duration and relative response rates in multiple schedule. Journal of the Experimental Analysis of Behavior, 17, 45-49.

Todorov, J. C. (1987). A Constituição como metacontingência. Psicologia: Ciência e Profissão, 7, 9-13.

Todorov, J. C. (2009). Behavioral analysis of non-experimental data associated with cultural practices. Behavior and Social Issues, 18, 10-14.

Todorov, J. C. (2012a). Metacontingências e a análise comportamental de práticas culturais. Clínica \& Cultura, 1(1), 36-45. 
Todorov, J. C. (2012b). Contingências de seleção cultural. Revista Brasileira de Análise do Comportamento, 8(2), 49-59.

Todorov, J. C. (2013). Conservation and transformation of cultural practices through contingencies and metaconitngencies. Behavior and Social Issues, 22, 64-73.

Todorov, J. C., \& Vianney, J. B. (2013). Xadrez (Versão 3.4.5) [Programa de computador]. Brasília, DF: Brasil.

Vasconcelos, I. G. (2014). Um procedimento experimental de modelagem de respostas para seleção do produto agregado em metacontingências. Dissertação de mestrado. Universidade de Brasília, Brasília, DF, Brasil.

Vichi, C. (2004). Igualdade ou desigualdade em pequeno grupo: um análogo experimental de manipulação de uma prática cultural. Dissertação de mestrado. Pontifícia Universidade Católica de São Paulo, São Paulo, SP, Brasil.

Vieira, M.C. (2010) Condições antecedentes participam de metacontingências? Dissertação de mestrado. São Paulo: Pontifícia Universidade Católica de São Paulo. 
ANEXOS 


\section{$\underline{A N E X O 1}$}

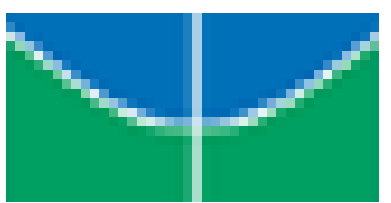

UNIVERSIDADE DE BRASÍLIA

Instituto de Psicologia

Departamento de Processos Psicológicos Básicos

Pós Graduação em Ciências do Comportamento

\section{Ficha de Identificação}

(Estas informações serão de uso restrito dos pesquisadores e não serão divulgadas)

Nome:

Idade:

E-mail:

Curso:

Semestre:

Já participou de pesquisas em psicologia anteriormente?

( ) $\operatorname{sim} \quad(\quad)$ não

Gostaria de receber informações posteriores sobre a pesquisa?

( ) $\operatorname{sim} \quad(\quad)$ não

Dias e horários disponíveis para participação na pesquisa: 


\section{ANEXO 2}

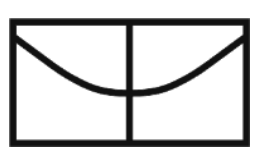

UNIVERSIDADE DE BRASÍLIA

DEPART. DE PROCESSOS PSICOLÓGICOS BÁSICOS - INSTITUTO DE PSICOLOGIA

\section{TERMO DE CONSENTIMENTO LIVRE E ESCLARECIDO}

Convidamos o(a) Sr(a) para participar da Pesquisa "Investigação sobre processos de discriminação operante na metacontingência" sob a responsabilidade da pesquisadora Rafaela Meireles Fontes Azevedo e sob orientação do Prof. João Cláudio Todorov, a qual pretende investigar comportamentos em situações de interação social.

Sua participação é voluntária e se dará por meio da participação em um jogo de computador a ser realizado em dupla.

Se depois de consentir em sua participação o $\operatorname{Sr}($ a) desistir de continuar participando, tem o direito e a liberdade de retirar seu consentimento em qualquer fase da pesquisa, seja antes ou depois da coleta dos dados, independente do motivo e sem nenhum prejuízo a sua pessoa. O caráter da sua participação é voluntário.

Os resultados da pesquisa serão analisados e publicados, mas sua identidade não será divulgada, sendo guardada em sigilo. Para qualquer outra informação, o(a) Sr(a) poderá entrar em contato com o pesquisador no endereço UNB-ICC Sul - Instituto de Psicologia - 
Laboratório AEC - Subsolo, pelo email: rafaelafontes@hotmail.com ou pelo telefone (61) 8279-5499.

Este projeto foi submetido ao CEP/IH Brasil para análise dos aspectos éticos envolvidos. As informações com relação à assinatura do TCLE ou os direitos do sujeito da pesquisa podem ser obtidos através do e-mail do CEP/IH cep_ih@unb.br.

Este documento foi elaborado em duas vias, uma ficará com o(a) pesquisador(a) responsável pela pesquisa e a outra com o senhor(a).

Consentimento Pós-Informação

$\mathrm{Eu}$ fui informado sobre o que o pesquisador quer fazer e porque precisa da minha colaboração, e entendi a explicação. Por isso, eu concordo em participar do projeto, sabendo que não vou ganhar nada e que posso sair quando quiser. Este documento é emitido em duas vias que serão ambas assinadas por mim e pelo pesquisador, ficando uma via com cada um de nós.

Data:

Assinatura do participante

Assinatura do Pesquisador Responsável 